\title{
Characterization of a thermodenuder-particle beam mass spectrometer system for the study of organic aerosol volatility and composition
}

\author{
A. E. Faulhaber ${ }^{1}$, B. M. Thomas ${ }^{1}$, J. L. Jimenez ${ }^{2}$, J. T. Jayne ${ }^{3}$, D. R. Worsnop ${ }^{3}$, and P. J. Ziemann ${ }^{1}$ \\ ${ }^{1}$ Air Pollution Research Center, University of California, Riverside, California, USA \\ ${ }^{2}$ Department of Chemistry and Biochemistry, and Cooperative Institute for Research in the Environmental Sciences (CIRES), \\ University of Colorado, Boulder, Colorado, USA \\ ${ }^{3}$ Aerodyne Research Inc., Billerica, Massachusetts, USA
}

Received: 4 August 2008 - Published in Atmos. Meas. Tech. Discuss.: 4 September 2008

Revised: 9 January 2009 - Accepted: 9 January 2009 - Published: 10 February 2009

\begin{abstract}
This paper describes the development and evaluation of a method for measuring the vapor pressure distribution and volatility-dependent mass spectrum of organic aerosol particles using a thermodenuder-particle beam mass spectrometer. The method is well suited for use with the widely used Aerodyne Aerosol Mass Spectrometer (AMS) and other quantitative aerosol mass spectrometers. The data that can be obtained are valuable for modeling organic gasparticle partitioning and for gaining improved composition information from aerosol mass spectra. The method is based on an empirically determined relationship between the thermodenuder temperature at which $50 \%$ of the organic aerosol mass evaporates $\left(T_{50}\right)$ and the organic component vapor pressure at $25^{\circ} \mathrm{C}\left(P_{25}\right)$. This approach avoids the need for complex modeling of aerosol evaporation, which normally requires detailed information on aerosol composition and physical properties. $T_{50}$ was measured for a variety of monodisperse, single-component organic aerosols with known $P_{25}$ values and the results used to create a $\log P_{25}$ vs. $T_{50}$ calibration curve. Experiments and simulations were used to estimate the uncertainties in $P_{25}$ introduced by variations in particle size and mass concentration as well as mixing with other components. A vapor pressure distribution and volatility-dependent mass spectrum were then measured for laboratory-generated secondary organic aerosol particles. Vaporization profiles from this method can easily be converted to a volatility basis set representation, which shows the distribution of mass vs. saturation concentration and
\end{abstract}

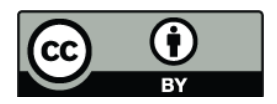

Correspondence to: P. J. Ziemann (paul.ziemann@ucr.edu) the gas-particle partitioning of aerosol material. The experiments and simulations indicate that this method can be used to estimate organic aerosol component vapor pressures to within approximately an order of magnitude and that useful mass-spectral separation based on volatility can be achieved.

\section{Introduction}

The volatility of atmospheric organic aerosol (OA) has been the subject of considerable attention recently (An et al., 2007; Robinson et al., 2007; Jonsson et al., 2007; Paulsen et al., 2006; Stanier et al., 2007; Huffman et al., 2009). It not only affects the mass concentration and composition of OA subjected to changing environments directly through gasparticle partitioning, but can also have a significant impact on aerosol chemistry. For example, it has been suggested (Robinson et al., 2007) that secondary organic aerosol (SOA) formed from the oxidation of semivolatile organic compounds that evaporate when primary organic aerosol (POA) is diluted in the atmosphere may explain recent field measurements of SOA concentrations well in excess of those predicted by models (de Gouw et al., 2005; Heald et al., 2005; Johnson et al., 2006; Volkamer et al., 2006).

The idea of incorporating realistic gas-particle partitioning into OA models by sorting the OA mass into bins based on volatility (Donahue et al., 2006) has had some success in bringing modeled geographic distributions of organic aerosol into agreement with observations (Robinson et al., 2007). In this scheme, components are binned according to their effective saturation concentrations, which can be estimated very simply from the vapor pressures of the pure components.

Published by Copernicus Publications on behalf of the European Geosciences Union. 
A reasonably accurate description of the gas-particle partitioning of the OA can be achieved by allowing each bin in the "volatility basis set" to cover one order of magnitude in effective saturation concentration. The distribution of mass within (gas vs. particle) and among the bins changes with emissions, dilution, temperature, and chemical transformation, with the fraction of mass in each bin that is in the particle phase depending on the effective saturation concentration and the total OA mass concentration according to gasparticle partitioning theory (Pankow, 1994a, b). Successful application of this approach requires measurements of $\mathrm{OA}$ volatility for a variety of conditions. However, there is currently no method available to measure the volatility distributions of ambient aerosol with order-of-magnitude accuracy, and the estimates commonly used in atmospheric models can be highly inaccurate (Huffman et al., 2009). Thus, the importance of having online techniques for measuring particle vapor pressure distributions is clear. A thermodenuder (TD), which is a flow-through system consisting of a heated vaporizer section in which particles evaporate, followed by a denuder section in which the vapor is removed by adsorption onto activated charcoal, is a useful tool for such measurements.

The Aerodyne Aerosol Mass Spectrometer (AMS) (Jayne et al., 2000; Jimenez et al., 2003) is widely used for mass spectrometric analysis of particulate matter in ambient studies. Its use in volatility studies to monitor changes in OA composition due to evaporation in a TD is practical, since the AMS can quantify total OA as well as specific OA components such as oxygenated OA (OOA) and hydrocarbonlike OA (HOA) (Zhang et al., 2005; Ulbrich et al., 2008) with high time-resolution and low detection limits. Two advantages of combining mass spectrometric detection with volatility measurements are apparent. First, relationships can be determined between composition and volatility in the aerosol being studied, allowing greater insight into the chemistry and therefore origin and chemical evolution of different volatility fractions. Second, the mass spectrum is simplified by the separation of volatility-resolved fractions. Atmospheric aerosol is generally an extremely complex mixture, and the composition of the organic fraction in particular is not well known or easy to characterize. A means of separating aerosol constituents online allows more information to be extracted from the mass spectra.

In this paper, we describe the characterization of a thermodenuder coupled to a thermal desorption particle beam mass spectrometer (TDPBMS) (Tobias et al., 2000), which serves as a surrogate AMS. An empirical method for estimating vapor pressure (i.e., $P_{25}$ ) distributions of $\mathrm{OA}$ using a calibration curve for $\log P_{25}$ vs. $T_{50}$ based on the TD vaporization profiles for several standard compounds is described, and its use is demonstrated for a simple OA mixture and for laboratory generated SOA. Volatility basis set analysis of the type used by Donahue et al. (2006) is used to show an alternative representation of the volatility distributions of these mixtures, and to predict their gas-particle partitioning. In addition, uncertainties in estimated vapor pressures, especially those due to the effects of OA mass concentration, particle size, and mixing state, which we have investigated through experiments and simulations, are discussed. The technique avoids many of the difficulties that would be encountered if modeling, rather than an empirical relationship, were used to extract vapor pressure distributions from the data. These include the need to have an accurate model of the detailed dynamics of the system and the need to use various properties of the particles and constituent compounds as input when even the identity of the compounds in the sample is unknown. It does, however, implicitly assume that these properties are adequately well represented by the particles of standard compounds used to calibrate the technique. Besides simple molecular parameters and particle properties such as size, shape, and mass concentration, these may include factors such as differences in evaporation coefficients, changes in evaporation coefficients with temperature (particularly if phase changes occur in the mixture), the mixing state of the particles, and the presence of oligomers or other unstable species that may undergo chemical changes with temperature. In addition, the technique can only give results as good as the vapor pressure data used in the calibration, and accurate vapor pressures for low volatility compounds are scarce. This introduces some additional uncertainty, especially for vapor pressures below the range covered by the calibration, for which extrapolated values must be used (although vapor pressures far below the calibration range are less important, as material with these vapor pressures will generally be found almost exclusively in the particle phase). Despite these limitations, it is shown that vapor pressures can be estimated to within one order of magnitude for a variety of samples.

\section{Experimental}

\subsection{Chemicals}

Methyl nitrite was synthesized by standard methods (Taylor et al., 1980). All other chemicals were purchased from Sigma-Aldrich. The chemicals and purities are as follows: pentadecanoic acid, 99+\%; hexadecanoic (palmitic) acid, 90\%; octadecanoic (stearic) acid, 95\%; butanedioic (succinic) acid, 99\%; hexanedioic (adipic) acid, 99\%; decandioic (sebacic) acid, 99\%; dioctyl sebacate (DOS), 90\%; oleic acid, $99 \%$; pentadecane, $99+\%$; isopropanol, $99.5 \%$.

\subsection{Aerosol generation}

Monodisperse aerosol particles were generated by atomizing a 0.05 to 0.6 volume $\%$ solution of the compounds of interest in 2-propanol. The solution was nebulized using a Collison atomizer with clean, dry air $(\mathrm{RH}<1 \%$, total hydrocarbons $<5 \mathrm{ppb}$ ) from an Aadco pure air generator. The resulting 


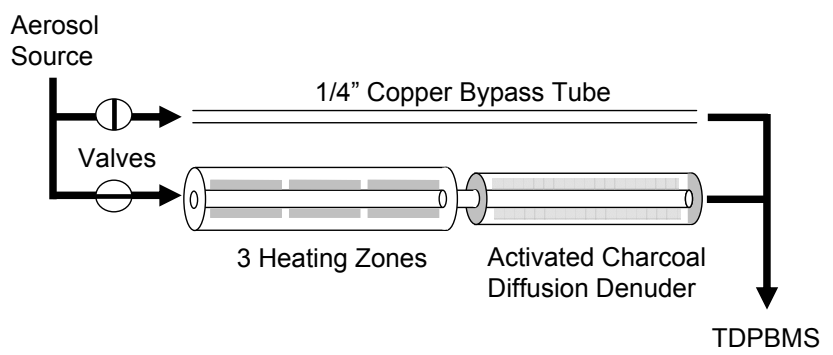

Fig. 1. Schematic of the thermodenuder (TD) system. The aerosol source is either an atomizer/DMA or an environmental chamber.

aerosol passed through two diffusion dryers filled with activated charcoal and a ${ }^{210}$ Po bipolar charger before being size selected using a differential mobility analyzer (DMA). The number density was measured at the beginning and end of each experiment using a Faraday cage aerosol electrometer positioned after the DMA.

Polydisperse oleic acid aerosol particles were generated using an evaporation/condensation particle generator. Pure oleic acid was evaporated in a heated flask into a stream of nitrogen and then mixed with another stream of nitrogen to initiate particle formation by homogeneous nucleation.

SOA was generated in a $\sim 6000 \mathrm{~L}$ PTFE environmental chamber. The chamber was initially filled with clean, dry air. For the reaction of pentadecane with $\mathrm{OH}$ radicals in the presence of $\mathrm{NO}_{\mathrm{x}}, 0.2 \mathrm{ppmv}$ pentadecane, $10 \mathrm{ppmv}$ methyl nitrite $\left[\mathrm{CH}_{3} \mathrm{ONO}\right]$, and $10 \mathrm{ppmv} \mathrm{NO}$ were added to the chamber and irradiated with blacklights to produce $\mathrm{OH}$ radicals (Atkinson et al., 1981). The blacklights were left on for $23 \mathrm{~min}$ to reach a mass concentration of $\sim 200 \mu \mathrm{g} \mathrm{m}^{-3}$. The mass concentration was measured using an SMPS (Wang and Flagan, 1990) comprised of a long differential mobility analyzer, a ${ }^{210} \mathrm{Po}$ bipolar charger, a TSI Model 3010 CPC, and scanning software provided by the McMurry group at the University of Minnesota.

\subsection{Thermodenuder}

The TD design, depicted in Fig. 1, is similar to that described by Wehner et al. (2002) and is described in detail by Huffman et al. (2008). It consists of a heated vaporizer section in which particles are volatilized, followed by a denuder section containing activated charcoal to remove the vapors. Each section is about $50 \mathrm{~cm}$ long. The vaporizer is heated using three heaters, each of which is independently regulated using a PID controller to achieve a fairly uniform temperature profile. Temperature feedback to the PID controllers is provided by thermocouples measuring the temperature on the exterior surface of the heating tube. The controllers were set to produce equal wall temperature readings for all three heating zones, which required set-points slightly higher than the wall temperature. For example, temperature set-points of $152.6,150.8$ and $153.5^{\circ} \mathrm{C}$ for the first,

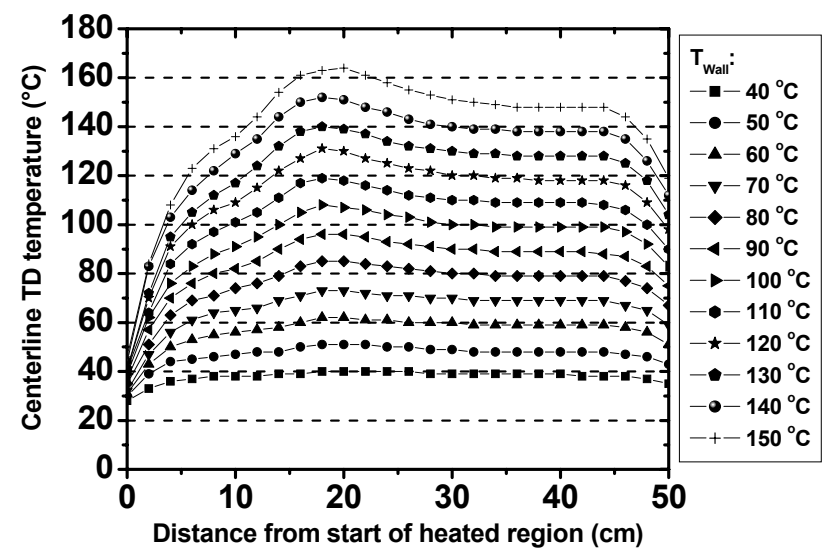

Fig. 2. Temperature profiles measured along the axis of the thermodenuder vaporizer section using a thermocouple probe. The temperatures given in the legend are the wall temperatures.

second, and third heating zones, respectively, were required for a wall temperature of $150^{\circ} \mathrm{C}$. The temperature profile within the vaporizer section of the TD was measured at several wall temperatures from 40 to $150^{\circ} \mathrm{C}$ using a thermocouple mounted in a $1 / 4$ inch diameter stainless steel tube. The thermocouple was positioned in the flow and out of contact with the inner wall, at a series of measured locations along the length of the vaporizer. A flow rate of $0.61 \mathrm{~min}^{-1}$, the same as that used in the aerosol volatility experiments, was used for this characterization. The resulting centerline temperature profiles are shown in Fig. 2. The profiles show an initial temperature rise, followed by a small bump, then a plateau before the temperature falls at the end of the heated region. The temperature in the plateau is $\sim 1-2^{\circ} \mathrm{C}$ below the wall temperature. For a wall temperature of $150^{\circ} \mathrm{C}$, at which the differences between the wall and centerline temperature are the greatest, the highest temperature in the initial bump is $\sim 14^{\circ} \mathrm{C}$ above the wall temperature, or $\sim 3 \%$ in terms of absolute temperature. These temperatures are somewhat lower and less uniform than those reported by Huffman et al. (2008), who found centerline temperatures $\sim 17 \%$ above the set-point measuring from room temperature for a TD of similar design (the TD used in this study was a prototype, and that used by Huffman et al. (2008) was built using feedback based on this model). The absolute temperatures are within $5 \%$ of the wall temperature for a distance of $\sim 40 \mathrm{~cm}$ between the cooler end regions.

Aerosol was sampled from either the atomizer/DMA or the environmental chamber, and, depending on the valve position, passed through either the TD or a bypass tube. A portion of the aerosol stream was then directed into the TDPBMS. The flow rate through the TD system was $0.61 \mathrm{~min}^{-1}$, set by adjusting a valve located directly upstream of a diaphragm pump. The resulting effective plug flow residence time in the central $40 \mathrm{~cm}$ of the vaporizer section was 
$\sim 15 \mathrm{~s}$ at room temperature. The flow rate was regularly measured with a Sensidyne Gilibrator. $M_{T}$, the aerosol mass concentration measured at the exit of the TD when set at temperature $T$, and $M_{0}$, the aerosol mass concentration measured at the exit of the TD bypass tube, were used to calculate the aerosol mass fractions remaining at a particular TD temperature, $M_{T} / M_{0}$. These values were the basis of the analysis employed in this study, and a TD vaporization profile consists of a plot of $M_{T} / M_{0}$ vs. $T$. Both changes in signal intensity, which occur due to changes in the aerosol mass concentration and signal drift in the mass spectrometer, and background signal must be accounted for in calculating $M_{T} / M_{0}$. The background signal, which arises from gas-phase species which are not completely removed by the pumping system, material slowly leaching from the vaporizer coating, and material from the particle beam that does not vaporize promptly (probably because it is deposited on other surfaces within the mass spectrometer), was measured by setting the DMA voltage to 0 for monodisperse aerosols (so that no particles exit the DMA), or by placing a Teflon filter in the line upstream of the TD for polydisperse aerosol and SOA. Since background variability was a major contribution to the uncertainty in $M_{T} / M_{0}$ for some of the systems studied, the background was measured frequently during the experiment, and the appropriate value to subtract from the signal at any time was estimated by interpolation. Background was subtracted from all signal intensities used in the calculations. In order to minimize the error due to drift in the aerosol signal over time, each pair of signal intensities used to calculate one value of $M_{T} / M_{0}$ was measured within a period of 4 to $5 \mathrm{~min}$. At each TD temperature, the flow was directed through the TD for approximately $4 \mathrm{~min}$. The signal measured at the beginning of the TD segment was divided by that measured just before the flow was switched from the bypass tube to the TD, and the signal measured at the end of the TD segment was divided by that measured just after the flow was switched back to the bypass tube (except for a period of about $90 \mathrm{~s}$ for the signal to equilibrate after switching each time). These two values were averaged to get a value of $M_{T} / M_{0}$ for that temperature. Between TD segments, the flow was directed through the bypass tube for $\sim 6-10 \mathrm{~min}$. Finally, $M_{T} / M_{0}$ was corrected for the temperature-dependent particle losses in the TD, as described by Huffman et al. (2008).

\subsection{Thermal desorption particle beam mass spectrometer}

The TDPBMS used in this study has been described in detail previously (Tobias et al., 2000), and will only be described here briefly. The aerosol is sampled through a $0.1 \mathrm{~mm}$ critical orifice, which results in a flow rate of $\sim 0.0751 \mathrm{~min}^{-1}$, and passes through a series of aerodynamic lenses that focus the particles into a beam. The beam then passes through a nozzle and two flat-plate skimmers and into the detection chamber, where particles impact on a V-shaped notch in a resistively heated copper vaporizer coated with a non-stick polymer. A

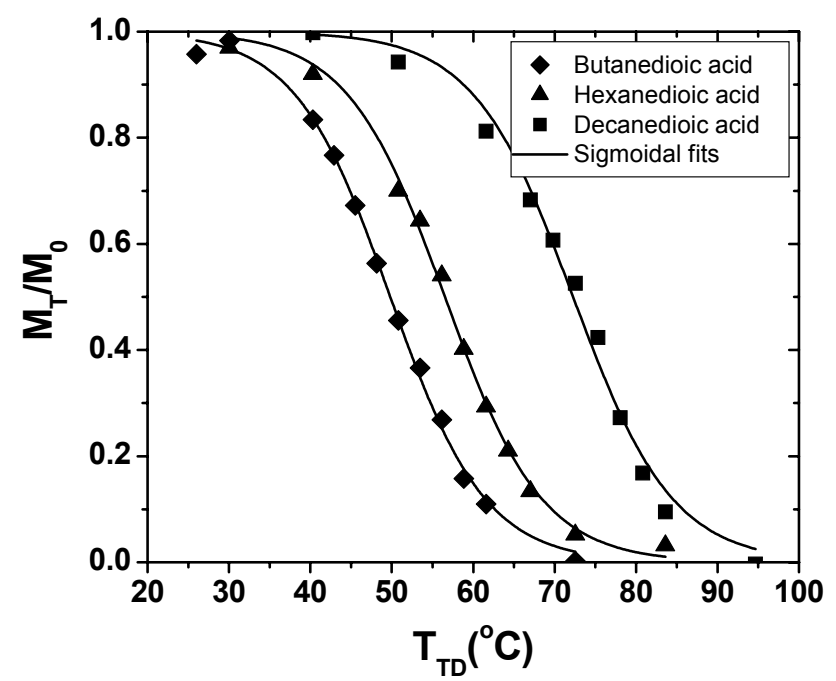

Fig. 3. Thermodenuder vaporization profiles for butanedioic $\left(\mathrm{C}_{4}\right)$, hexanedioic $\left(\mathrm{C}_{6}\right)$, and decanedioic $\left(\mathrm{C}_{10}\right)$ acids. The solid lines are sigmoidal fits to the data.

fraction of the vaporized material diffuses into an ABB Extrel MEXM 500 quadrupole mass spectrometer and is ionized by $70 \mathrm{eV}$ electrons, mass analyzed, and detected using a pulse-counting detector. In the experiments described here, the vaporizer was held at a temperature of $160^{\circ} \mathrm{C}$ in order to vaporize all organic aerosol components rapidly and obtain mass spectral data in real time. For the pure compounds used for calibration and the simple mixture, the signal intensity at a few strong peaks was monitored in single ion monitoring (SIM) mode. For SOA, complete scans were recorded, and the TI (total ion) signal calculated for masses between $\mathrm{m} / \mathrm{z} 45$ and an upper limit between $\mathrm{m} / \mathrm{z}, 260$ and 400, depending on the aerosol composition.

\section{Results, analysis and discussion}

\subsection{Thermodenuder vaporization profiles}

Figure 3 shows a plot of $M_{T} / M_{0}$, the fraction of the particle mass remaining after heating in the TD, vs. TD temperature for three dicarboxylic acids along with sigmoidal fits to the data. A plot of $M_{T} / M_{0}$ vs. TD temperature will be referred to as a TD vaporization profile. The values of $T_{\mathrm{TD}}$ on the $x$ axis refer to the temperatures measured on the outside of the TD flow tube, i.e., the wall temperatures. As mentioned above, the temperatures measured in the flow are within $15 \%$ of the wall temperatures for a distance of about $40 \mathrm{~cm}$ within the TD, with the remainder of the length of the TD heating region consisting of the temperature rise and fall regions.

$T_{50}$, the temperature at which half of the aerosol mass has evaporated, is a convenient temperature with which to characterize a pure standard compound. The temperature at the 


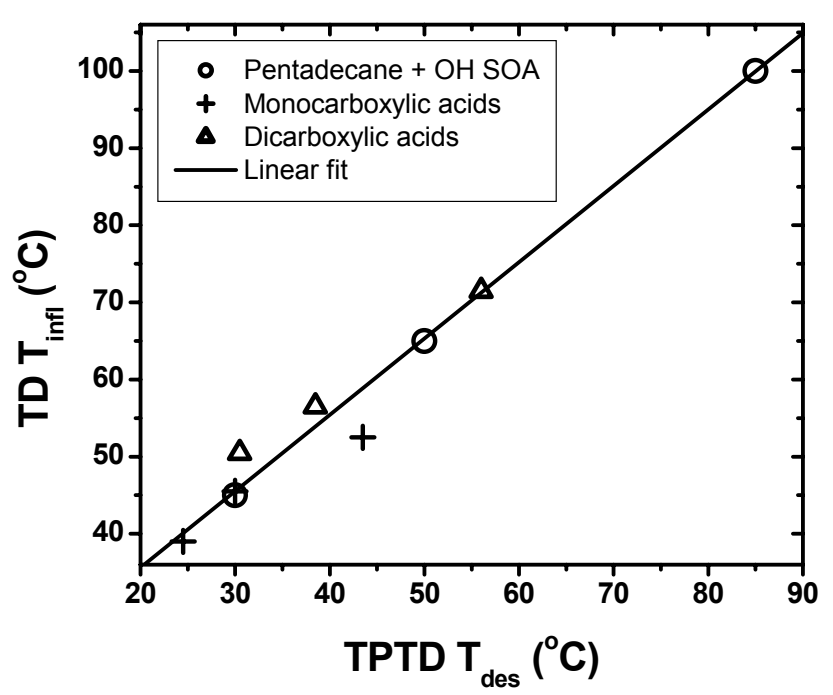

Fig. 4. $T_{\text {infl }}$, the inflection point temperature in the TD vaporization profile, vs. $T_{\text {des }}$, the temperature of the peak in the TPTD desorption profile. The line shows the linear least squares fit accounting for errors in both $T_{\text {infl }}$ and $T_{\text {des }}$ (York et al., 2004).

midpoint of the sigmoidal fit is used to determine $T_{50}$ for the standard compounds. While the TD vaporization profiles are not strictly sigmoidal, the fit allows for variation in midpoint and width, the two characteristics that differ between compounds, and avoids much of the error due to scatter that would be introduced if $T_{50}$ were estimated by interpolation. $T_{\text {infl, }}$, the inflection point in the TD vaporization profile, corresponds to the peak in the aerosol mass evaporation rate, and is approximated here by the maximum in $-d\left(M_{T} / M_{0}\right) / d T_{\mathrm{TD}}$ after smoothing. $T_{50}$ tends to be slightly lower than $T_{\text {infl }}$ (by $\sim 1-2^{\circ} \mathrm{C}$ ) for pure compounds.

Vaporization profiles of mixtures reflect the volatility distribution and interactions among the components, as discussed below. Volatility distributions of mixtures have been studied previously in this laboratory using temperatureprogrammed thermal desorption (TPTD), an offline technique in which particles are collected on a cold vaporizer and then the temperature is slowly increased as the mass spectrum of the evaporating material is monitored (Tobias and Ziemann, 1999). In TPTD, the signal intensity is proportional to the evaporation rate, and a desorption (TI signal vs. temperature) profile obtained using this technique is similar to the temperature derivative of a TD vaporization profile. Figure 4 shows $T_{\text {infl }}$ from TD vaporization profiles plotted against $T_{\text {des }}$, the TPTD peak desorption temperature, for several mono- and dicarboxylic acids and features in the vaporization profile for chamber-generated SOA from the reaction of pentadecane with $\mathrm{OH}$ (Lim and Ziemann, 2005). The TD $T_{\text {infl }}$ is uniformly higher than the TPTD $T_{\text {des }}$ by $\sim 16^{\circ} \mathrm{C}$, and after correcting for this temperature offset, the two techniques show very good agreement (the slope of the linear

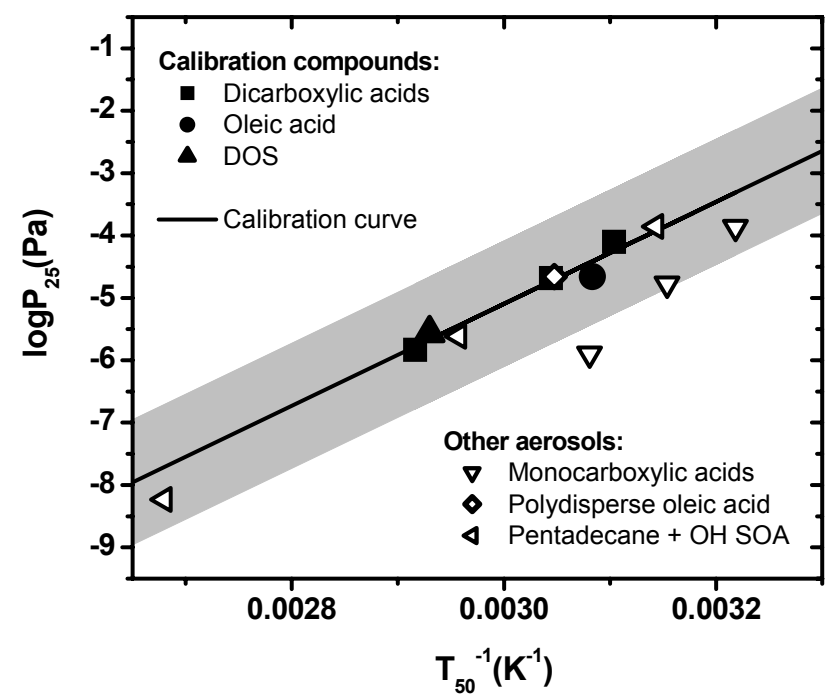

Fig. 5. $\log P_{25}$ vs. $T_{50}^{-1}$ calibration plot. The $T_{50}$ values were calculated as described in the text. For the calibration compounds (solid symbols) $200 \mathrm{~nm}$ diameter particles and mass concentrations of $100-200 \mu \mathrm{g} \mathrm{m}^{-3}$ were used. $T_{50}$ values for various other aerosols used in this study are shown as open symbols. The shaded region indicates the region \pm 1 order of magnitude in $P_{25}$ from the calibration curve (solid line).

fit shown in Fig. 4 is $0.99 \pm 0.04$ ). The temperature offset is primarily due to the difference in evaporation timescales for the two techniques. In TPTD analysis, $T_{\text {des }}$ is typically reached in $\sim 5 \mathrm{~min}$ for the standard temperature ramp rate of $2^{\circ} \mathrm{C} \mathrm{min}^{-1}$. In TD analysis, $T_{\text {infl }}$ is the temperature at which approximately the same fraction of the particle mass evaporates in the $\sim 10 \mathrm{~s}$ transit through the TD. In order to compensate for the much shorter time available for evaporation in the TD, the particle vapor pressure must be higher, which requires that $T_{\text {infl }}$ be higher than $T_{\text {des. }}$. A more quantitative analysis of the effects of particle properties and measurement parameters on this temperature difference could be carried out using the evaporation models employed here for the TD and the one used previously for modeling TPTD evaporation (Chattopadhyay and Ziemann, 2005). The agreement between the two techniques allows TPTD desorption profiles to be used in the interpretation of ambient data obtained with the TD. A database of TD and TPTD vaporization profiles for various classes of chamber-generated SOA, including profiles for characteristic ions in many cases, is available online at http://cires.colorado.edu/jimenez-group/TDPBMSsd/ for use in the analysis of TD-AMS data. The similarity between the TPTD desorption profile and the temperature derivative of a TD vaporization profile is illustrated in more detail below in Sect. 3.7. 


\section{$3.2 \log P_{25}$ vs. $T_{50}$ calibration}

A plot of $\log P_{25}$ vs. $T_{50}^{-1}$ for the standard compounds used in this study is shown in Fig. 5. The $T_{50}$ measurements were made using size-selected $200 \mathrm{~nm}$ diameter particles at mass concentrations of $100-200 \mu \mathrm{g} \mathrm{m}^{-3}$. Values of $P_{25}$ were taken from the literature and are given in Table 1 . The literature values used were restricted to studies in which the particles were generated by atomization of a solution, as they were for the particles used in the calibration, in order to avoid any bias due to the effect of residual solvent. The line is the linear least squares fit with errors in both $T_{50}^{-1}$ and $\log P_{25}$ taken into account (York et al., 2004) and is given by the equation

$\log P_{25}(\mathrm{~Pa})=8171 T_{50}^{-1}\left(\mathrm{~K}^{-1}\right)-29.61$

The standard deviation in $\log P_{25}$ is $\sim 0.2$, so the uncertainty in calculating $P_{25}$ for an unknown compound with similar particle size, shape and mass concentration from this curve should be roughly 0.2 orders of magnitude within the range covered by the model compounds, and increase somewhat with extrapolation. The model compounds consist of both solids and liquids, with a variety of functionalities (saturated dicarboxylic acids, an unsaturated monocarboxylic acid, and a diester), showing that a reasonable fit can be obtained for a set of pure organic compounds with different physical and chemical properties. Since variations in temperature profiles can be expected for individual TDs, even those sharing the same design, the $\log P_{25}$ vs. $T_{50}^{-1}$ calibration may vary from one TD to another. Therefore, in order for $P_{25}$ to be estimated accurately using this technique, separate calibrations should be carried out for individual TDs. The set of standard compounds listed in Table 1 is well suited to the calibration of TDs to be used in vapor pressure measurements of atmospheric aerosol. Mass loadings higher than those typically found in ambient conditions were used in this study, since the TDPBMS has lower sensitivity than particle mass spectrometers usually used in ambient studies. The choice of particle size and mass concentration will affect the calibration, as is discussed further in the following section.

Figure 5 shows measured values of $T_{50}$ for several other aerosols, along with a shaded region encompassing the region 1 order of magnitude in $P_{25}$ above and below the calibration curve (Eq. 1). The aerosols represented in the figure are monocarboxylic acids with particle diameters of $200 \mathrm{~nm}$ and mass concentrations of $150-200 \mu \mathrm{g} \mathrm{m}^{-3}$, polydisperse oleic acid particles with a mass distribution peaking at $\sim 500 \mathrm{~nm}$ and mass concentration of $\sim 250 \mu \mathrm{g} \mathrm{m}^{-3}$, and a laboratory-generated SOA from the reaction of pentadecane with $\mathrm{OH}$ (in the case of the SOA, $T_{\text {infl for features in the va- }}$ porization profile were used in place of $T_{50}$ ), as well as the standard compounds used in the calibration. The literature values of $P_{25}$ used in the plot are listed in Tables 1 and 2, except those for the SOA features, which are based on a TPTD study of the same aerosol (Lim and Ziemann, 2005) and a
Table 1. $P_{25}$ values from the literature for compounds used in the calibration.

\begin{tabular}{lcc}
\hline Compound & $P_{25}(\mathrm{~Pa})$ & Reference \\
\hline Pentadecanoic acid & $1.75 \times 10^{-4}$ & $\mathrm{a}$ \\
& $1.05 \times 10^{-4}$ & $\mathrm{~b}$ \\
Hexadecanoic acid & $2.66 \times 10^{-5}$ & $\mathrm{a}$ \\
& $1.06 \times 10^{-5}$ & $\mathrm{~b}$ \\
Octadecanoic acid & $2.83 \times 10^{-6}$ & $\mathrm{a}$ \\
& $5.64 \times 10^{-7}$ & $\mathrm{~b}$ \\
Butanedioic acid & $1.37 \times 10^{-4}$ & $\mathrm{a}$ \\
& $4.60 \times 10^{-5}$ & $\mathrm{c}$ \\
Hexanedioic acid & $3.02 \times 10^{-5}$ & $\mathrm{a}$ \\
& $1.48 \times 10^{-5}$ & $\mathrm{~b}$ \\
Decanedioic acid & $1.42 \times 10^{-5}$ & $\mathrm{c}$ \\
DOS & $2.74 \times 10^{-6}$ & $\mathrm{a}$ \\
Oleic acid & $2.10 \times 10^{-6}$ & $\mathrm{~d}$ \\
\hline
\end{tabular}

a Chattopadhyay and Ziemann (2005), b Tao and McMurry (1989),

${ }^{c}$ Bilde et al. (2003), ${ }^{d}$ Rader et al. (1987)

calibration described below in Sect. 3.7. With the exception of the $\mathrm{C}_{18}$ monocarboxylic acid, the literature values of $P_{25}$ for all the aerosols fall within 1 order of magnitude of the values predicted by the calibration. The generally low values of $T_{50}$ for the monoacids may be due to differences in particle shape. Crystals of these compounds are often scaly, and it is possible that the particles they form by evaporation of the droplets from the atomizer are similarly thin and flat, and thus have a considerably greater surface area to volume ratio than the other particles, which would lead to faster evaporation. The effects of variations in particle size and mass loading, as well as dilution with other compounds in a mixed particle, on $T_{50}$, are addressed in more detail below.

The spread in the literature values increases significantly with decreasing vapor pressure due to the difficulty in measuring very low vapor pressures, and values obtained by extrapolating to lower vapor pressures than those covered by the calibration (below $\sim 10^{-6} \mathrm{~Pa}$ ) are less reliable. Donahue et al. (2006) suggest that compounds with vapor pressures as low as $10^{-8} \mathrm{~Pa}$ should be considered semivolatile. Estimating the vapor pressures of such compounds would entail extrapolating by about 2 orders of magnitude in $P_{25}$, which could introduce a significant error. While it would be desirable to accurately estimate vapor pressures of ambient aerosols down to $10^{-8} \mathrm{~Pa}$, this will only be possible when vapor pressures in this range are known with greater certainty.

\subsection{Effects of particle size and mass concentration}

Particle size and mass concentration affect both evaporation rates and equilibrium partitioning, and so are expected to 
Table 2. Parameters used in the simulations of $T_{50}$ vs. mass concentration and $M_{T} / M_{0}$ vs. $T_{\mathrm{TD}}$.

\begin{tabular}{|c|c|c|c|c|c|c|c|}
\hline & $\begin{array}{c}M W \\
\left(\mathrm{~g} \mathrm{~mol}^{-1}\right)\end{array}$ & $\begin{array}{c}\rho \\
\left(\mathrm{g} \mathrm{cm}^{-3}\right)\end{array}$ & $\begin{array}{l}P_{25} \\
(\mathrm{~Pa})\end{array}$ & $\begin{array}{l}\Delta H_{\mathrm{vap}, 25^{\circ} \mathrm{C}} \\
\left(\mathrm{kJ} \mathrm{mol}^{-1}\right)^{\mathrm{b}}\end{array}$ & $\begin{array}{l}T_{c} \\
(\mathrm{~K})\end{array}$ & $\omega$ & $\begin{array}{c}D_{v, 25^{\circ} \mathrm{C}} \\
\left(\mathrm{m}^{2} \mathrm{~s}^{-1}\right)^{\mathrm{c}}\end{array}$ \\
\hline Oleic acid ${ }^{\mathrm{a}}$ & 282.5 & 0.891 & $2.1 \times 10^{-5 \mathrm{~g}}$ & $129 \mathrm{~g}$ & $819^{d}$ & $1.19^{\mathrm{e}}$ & $3.22 \times 10^{-6 f}$ \\
\hline Pentadecanoic acid & 242.2 & 0.843 & $1.36 \times 10^{-4 \mathrm{~h}, \mathrm{i}}$ & $154.0^{\mathrm{h}, \mathrm{i}}$ & $790^{\mathrm{d}}$ & $1.04^{\mathrm{e}}$ & $3.59 \times 10^{-6 \mathrm{f}}$ \\
\hline Hexadecanoic acid & 256.4 & 0.853 & $1.68 \times 10^{-5 \mathrm{~h}, \mathrm{i}}$ & $155.7^{\mathrm{h}, \mathrm{i}}$ & $800^{d}$ & $1.11^{\mathrm{e}}$ & $3.43 \times 10^{-6 \mathrm{f}}$ \\
\hline Octadecanoic acid & 284.5 & 0.941 & $1.24 \times 10^{-6 \mathrm{~h}, \mathrm{i}}$ & $174.25^{\mathrm{h}, \mathrm{i}}$ & $819^{d}$ & $1.24^{\mathrm{e}}$ & $3.19 \times 10^{-6 \mathrm{f}}$ \\
\hline Eicosanoic acid & 312.5 & 0.824 & $3.25 \times 10^{-7 \mathrm{~h}}$ & $148.4^{\mathrm{h}}$ & $837^{\mathrm{d}}$ & $1.36^{\mathrm{e}}$ & $2.98 \times 10^{-6 f}$ \\
\hline \multicolumn{8}{|c|}{ Hypothetical compounds for simulation in Fig. 7} \\
\hline & 300 & 0.85 & $8.26 \times 10^{-8}$ & 151.6 & 827 & 1.3 & $3.00 \times 10^{-6}$ \\
\hline & 300 & 0.85 & $8.26 \times 10^{-7}$ & 145.8 & 813 & 1.2 & $3.21 \times 10^{-6}$ \\
\hline & 300 & 0.85 & $8.26 \times 10^{-6}$ & 140.0 & 799 & 1.1 & $3.41 \times 10^{-6}$ \\
\hline & 300 & 0.85 & $8.26 \times 10^{-5}$ & 134.2 & 785 & 1.0 & $3.62 \times 10^{-6}$ \\
\hline
\end{tabular}

a Adjusted parameters used for oleic acid in Fig. 6 only: $P_{25}=2.2 \mathrm{E}-5 \mathrm{~Pa}, \Delta H_{\mathrm{vap}}\left(25^{\circ} \mathrm{C}\right)=137 \mathrm{~kJ} / \mathrm{mol}$. For the free-molecule model, $\alpha$ was set to 1 .

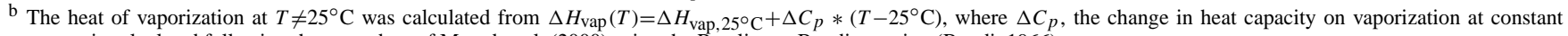
pressure, is calculated following the procedure of Morad et al. (2000) using the Rowlinson-Bondi equation (Bondi, 1966).

c The temperature dependence of $D_{v}$ was approximated as $D_{v}(T) / D_{v, 25^{\circ} \mathrm{C}}=(T / 298.15 \mathrm{~K})^{2}$ (Reid et al., 1987).

${ }^{\mathrm{d}} T_{C}$, critical temperature, from Fedor's method (Reid et al., 1987).

e $\omega$, accentric factor, from critical properties calculated from Joback's method (Joback and Reid, 1987; Reid et al., 1987).

${ }^{\mathrm{f}} D_{v}\left(25^{\circ} \mathrm{C}\right)$ from the Chapman-Enskog equation (Rader et al., 1987; Reid et al., 1987).

${ }^{g}$ Rader et al. (1987)

h Chattopadhyay and Ziemann (2005)

i Tao and McMurry (1989)

influence the TD vaporization profiles obtained using this technique. Experiments and simulations were therefore performed to investigate the dependence of $T_{50}$ on these quantities. $T_{50}$ was measured for oleic acid particles with diameters of 100, 200, 300, and $400 \mathrm{~nm}$ and several mass concentrations between 30 and $500 \mu \mathrm{g} \mathrm{m}^{-3}$ and simulated for the same particle diameters, and mass concentrations of 1$600 \mu \mathrm{g} \mathrm{m}^{-3}$. Since it cannot be assumed that the particles reach equilibrium in the TD in all cases, dynamic models for two mass transport regimes were used in the simulations. Simulations of particle evaporation were performed using equations for the rate of change in particle diameter, $d_{p}$, in the free-molecule $\left(d_{p} \ll \lambda\right)$

$d\left(d_{p}\right) / d t=2 \alpha M W\left(P_{\infty}-P_{d}\right) /\left[\rho(2 \pi M W R T)^{1 / 2}\right]$

and continuum $\left(d_{p} \gg \lambda\right)$

$d\left(d_{p}\right) / d t=4 D_{v} M W\left(P_{\infty}-P_{d}\right) /\left(\rho d_{p} R T\right)$

regimes, where $\alpha, D_{v}, P_{\infty}, P_{d}, M W, \rho$ are the evaporation coefficient, gas phase diffusion coefficient, partial pressure, equilibrium vapor pressure for a particle with diameter $d$, molecular weight, and condensed-phase density of the evaporating compound, $\lambda$ is the mean free path of a vapor molecule of the evaporating compound, $t$ is the time, $T$ is the TD temperature in $\mathrm{K}$, and $R$ is the gas constant (Seinfeld and Pandis, 1998). The parameter values used in the simulations are given in Table 2. The parameters used for oleic acid in the simulation were altered somewhat from literature values and the effective residence time was reduced from 15 to $6.5 \mathrm{~s}$ for all simulations in this paper. It should be noted that reducing $\alpha$ from 1 to 0.3 in Eq. (2) or including the Fuchs-Sutugin correction factor (Seinfeld and Pandis, 1998) with an evaporation coefficient of 0.2 in Eq. (3) has a similar effect to reducing the effective residence time. These changes are not unreasonable, since the model does not account for all the complexities of the system, and they yielded better fits to the data while not altering the major conclusions derived from the simulations. The integrated value of $d_{p}$ was calculated at intervals of $10 \mathrm{~ms}$ over the residence time of the aerosol in the heated region. $T_{50}$ was determined by varying the temperature and repeating the calculation above until the fraction of mass remaining converged to 0.5 within a tolerance of $10^{-6}$. The effect of mass concentration was accounted for in the simulation by calculating $P_{\infty}$ at each time step, using the mass of aerosol evaporated at that step, and assuming ideal behavior. The changes in the gas phase diffusion coefficient, the heat of vaporization, and the residence time in the heated region (due to thermal expansion) with increasing temperature were accounted for. In these simulations the Kelvin effect was ignored, since even for the smallest oleic acid particle considered, one of $80 \mathrm{~nm}$ formed by evaporation of $50 \%$ of the mass from a $100 \mathrm{~nm}$ particle, the increase in the vapor pressure due to surface tension (assuming a value of $0.03 \mathrm{~J} \mathrm{~m}^{-2}$ from Tao and McMurry, 1989 ) is only $\sim 20 \%$. The model is not intended to reproduce all the details of particle evaporation in the TD, such as the longitudinal and cross-sectional variation in temperature and gas flow rate, and evaporation and re-condensation that takes place in the charcoal denuder region. Such details would be 


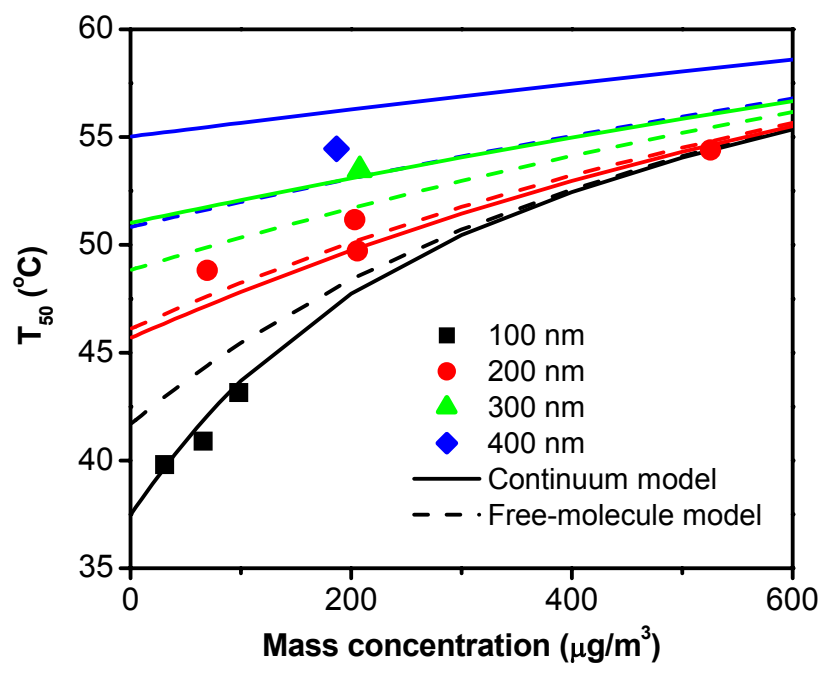

Fig. 6. Measured and simulated values of $T_{50}$ vs. particle mass concentration for $100,200,300$, and $400 \mathrm{~nm}$ diameter oleic acid particles. The different colors indicate different particle sizes. The solid lines are the results of the continuum model, and the dashed lines are the results of the free-molecule model.

necessary if the model was being used in an attempt to determine molecular parameters by fitting experimental data, but for the present purpose of describing trends in the data, such a rigorous description of the system is unnecessary.

As shown in Fig. 6 for both the measurements and simulations, $T_{50}$ increases as either the particle size or the mass concentration increases. The effect of particle diameter on $T_{50}$ is apparent in the experimental data for mass concentrations up to at least $300-400 \mu \mathrm{g} \mathrm{m}^{-3}$. The continuum model captures the trends in the data with respect to both particle diameter and mass concentration. For the $200 \mathrm{~nm}$ particles, both the models fit the data fairly well, but for smaller and larger particles only the continuum model tracks the increase in $T_{50}$ with particle diameter well. This is reasonable, since for this model the maximum correction for non-continuum effects, calculated for $80 \mathrm{~nm}$ particles using the theory of Fuchs and Sutugin (1971), only decreases the calculated evaporation rate by $\sim 20 \%$. Not only are the Kelvin and non-continuum effects small, but they have compensating effects on evaporation rates.

The good agreement between measurements and simulations provides support for the use of the continuum model to explain and predict particle behavior in the TD. For example, some useful insights can be gained by considering the case where $P_{\infty}$ is negligibly small compared to $P_{d}$. Integrating Eq. (3) explicitly with respect to $t$ and solving for the case where $d_{p} / d_{p, 0}=(1 / 2)^{1 / 3}$, the value of the diameter ratio when the initial mass has been reduced by $50 \%$, gives the following equation

$$
P_{d}\left(T_{50}\right) / T_{50}=d_{p, 0}^{2} \rho R\left[1-(1 / 2)^{2 / 3}\right] /\left(8 D_{v} M W t_{r}\right)
$$

where $d_{p, 0}$ is the initial particle diameter and $t_{r}$ is the residence time in the TD. Without solving explicitly for $T_{50}$, it is possible to get some insight into its dependence on $d_{p, 0}$ by noting explicitly the temperature dependence of the particle vapor pressure, $P_{d}\left(T_{50}\right)$, as given by the Clausius-Clapeyron equation

$P_{d}\left(T_{50}\right)=P_{25} \exp \left[-\Delta H_{\mathrm{vap}} / R\left(1 / T_{50}-1 / 298.15 \mathrm{~K}\right)\right]$

where $\Delta H_{\text {vap }}$ is the heat of vaporization. Because $P_{d}\left(T_{50}\right)$ depends exponentially on $T_{50}$, the change in $T_{50}$ that occurs as the result of a change in $d_{p, 0}$ is determined primarily through the $P_{d}\left(T_{50}\right)$ term in Eq. (4) rather than $T_{50}$ in the denominator. Hence, if $d_{p, 0}$ is doubled, the factor of 4 increase in $P_{d}\left(T_{50}\right) / T_{50}$ introduced by the $d_{p, 0}^{2}$ term is primarily compensated for by a proportionately much smaller increase in $T_{50}$ that is amplified through the $P_{d}\left(T_{50}\right)$ term. For example, at low aerosol mass concentrations where $P_{\infty}$ is very small and Eq. (4) is applicable, the ratio of $T_{50}$ values (in K) for the continuum model shown in Fig. 6 for 400 and $100 \mathrm{~nm}$ particles is only $\sim 1.05$ while the square of the diameter ratio is 16 . In addition, the increase in $T_{50}$ with increased aerosol mass concentration that is observed in Fig. 6 can be understood by noting that for a given initial and final particle diameter, more vapor is formed at a higher aerosol mass concentration. This increases $P_{\infty}$, which decreases the evaporation rate according to Eq. (3), meaning that higher TD temperatures are required for particles to lose $50 \%$ of their mass.

The $\log P_{25}$ vs. $T_{50}$ calibration equation, as mentioned above, was calculated using data from particles with $d_{p}=200 \mathrm{~nm}$ and mass concentrations of $100-200 \mu \mathrm{g} \mathrm{m}^{-3}$. The error incurred by using this calibration for particles with other diameters and mass concentrations can be estimated using the simulation results. As shown in Fig. 6, continuum model simulations indicate that $T_{50}$ values for particles with the same composition and initial diameters and mass concentrations anywhere in the range from $100-400 \mathrm{~nm}$ and $1-600 \mu \mathrm{g} \mathrm{m}^{-3}$ will differ by less than $\sim 11^{\circ} \mathrm{C}$ from those at $200 \mathrm{~nm}$ and $150 \mu \mathrm{g} \mathrm{m}^{-3}$, which is roughly the average for the calibration particles. For this range of conditions, which captures those typically encountered in the atmosphere and in the laboratory, the maximum error incurred by calculating $P_{25}$ using the calibration (Eq. 1) and a measured value of $T_{50}$ that is uncorrected for particle size and mass concentration would therefore be about a factor of 9 in $P_{25}$ (this is based on an $11^{\circ} \mathrm{C}$ difference at the low end of the $T_{50}$ range, where the change in $\log P_{25}$ with $T_{50}$ is the greatest). The magnitude of the error for any complex aerosol will vary with particle composition, phase, morphology, and mixing state, factors that are generally unknown and are therefore difficult or impossible to account for in simulations. Ambient organic particle mass concentrations are nearly always lower than the range used in the determination of the calibration curve given by Eq. (1)., and the effect of particle size on the evaporation kinetics is most pronounced at low mass concentrations. For calibrations to be used for ambient studies, therefore, the 
choice of particle size is important. From Eqs. (4) and (5), it can be shown that $T_{50}^{-1}$ is roughly linear with respect to $\log d_{p}$. Therefore, the mean of the mass distribution with respect to $\log d_{p}$ expected for an ambient study along with a typical ambient mass concentration are ideal for calibration of a TD.

\subsection{Vapor pressure distributions}

The derivative of $M_{T} / M_{0}$ for a mixture with respect to $T_{\mathrm{TD}}^{-1}$, the inverse of the TD temperature in $\mathrm{K}$, is a good proxy for a vapor pressure distribution, since the $T_{\mathrm{TD}}$ at the median in the derivative of the signal for a particular compound is equal to $T_{50}$, from which the vapor pressure can be calculated from the calibration curve. The distribution calculated in this way shows the relative amount of condensed phase material vs. vapor pressure, and since the TI signal is approximately proportional to mass (Crable and Coggeshall, 1958), the intensity is proportional to the mass concentration. For a mixture of compounds, the vapor pressure distribution is a conceptually useful representation of the data that can be obtained with the TD-mass spectrometer.

To generate such a plot from a TD vaporization profile, the $M_{T} / M_{0}$ curve is numerically differentiated with respect to $T_{\mathrm{TD}}^{-1}$, and the x-axis is then converted from $T_{\mathrm{TD}}^{-1}$ to $\log P_{25}$ using the $\log P_{25}$ vs. $T_{50}$ calibration, i.e., Eq. (1), with $T_{50}$ replaced with $T_{\mathrm{TD}}$. Multiplying $d\left(M_{T} / M_{0}\right) / d\left(T_{\mathrm{TD}}^{-1}\right)$ by the Jacobian, which is simply the inverse of the slope in Eq. (1), yields the normalized log-scale mass vs. vapor pressure distribution, $M\left(\log P_{25}\right)$. The intensity is, of course, convoluted with the shape of the TD vaporization profile for the individual components, and the vapor pressure of a component in a mixture is not generally equal to $P_{25}$ for the pure compound, but is affected by the mixing state. The effect of these approximations and others are discussed in detail in Sect. 3.5. Center-point differentiation (i.e., for data-point $i$, $\left.d\left(M_{T} / M_{0}\right) /\left.d\left(T_{\mathrm{TD}}^{-1}\right)\right|_{T i}=\left(\left(M_{T i+1} / M_{0}\right)-\left(M_{T i-1} / M_{0}\right)\right) /\left(T_{i+1}^{-1}-T_{i-1}^{-1}\right)\right)$ was found to be optimal for the experimental datasets in this study.

Figure 7 shows (a) $M_{T} / M_{0}$ vs. $T_{\mathrm{TD}}^{-1}$, which is equivalent to the TD vaporization profile with the $\mathrm{x}$-axis changed from $T_{\mathrm{TD}}$ to $T_{\mathrm{TD}}^{-1}$ and (b) $-d\left(M_{T} / M_{0}\right) / d\left(T_{\mathrm{TD}}^{-1}\right)$ (left and bottom axis) and the normalized $\log P_{25}$ distribution (right and top axis) calculated as described above for a hypothetical internally mixed aerosol consisting of four compounds. For simulated TD vaporization profiles, $T_{\mathrm{TD}}$ was converted to $\log P_{25}$ using a calibration based on simulated $T_{50}$ vs. input $\log P_{25}$ in order to account for differences between experimental and simulated $T_{50}$ values for the same (literature or input) molecular properties. The TD vaporization profile was simulated using a continuum model as described above, and the parameters used in the calculation are shown in Table 2. The $P_{25}$ values and relative mass concentrations of the different compounds used in the simulation are shown as vertical lines in the $\log P_{25}$ distribution. Some differences between the input

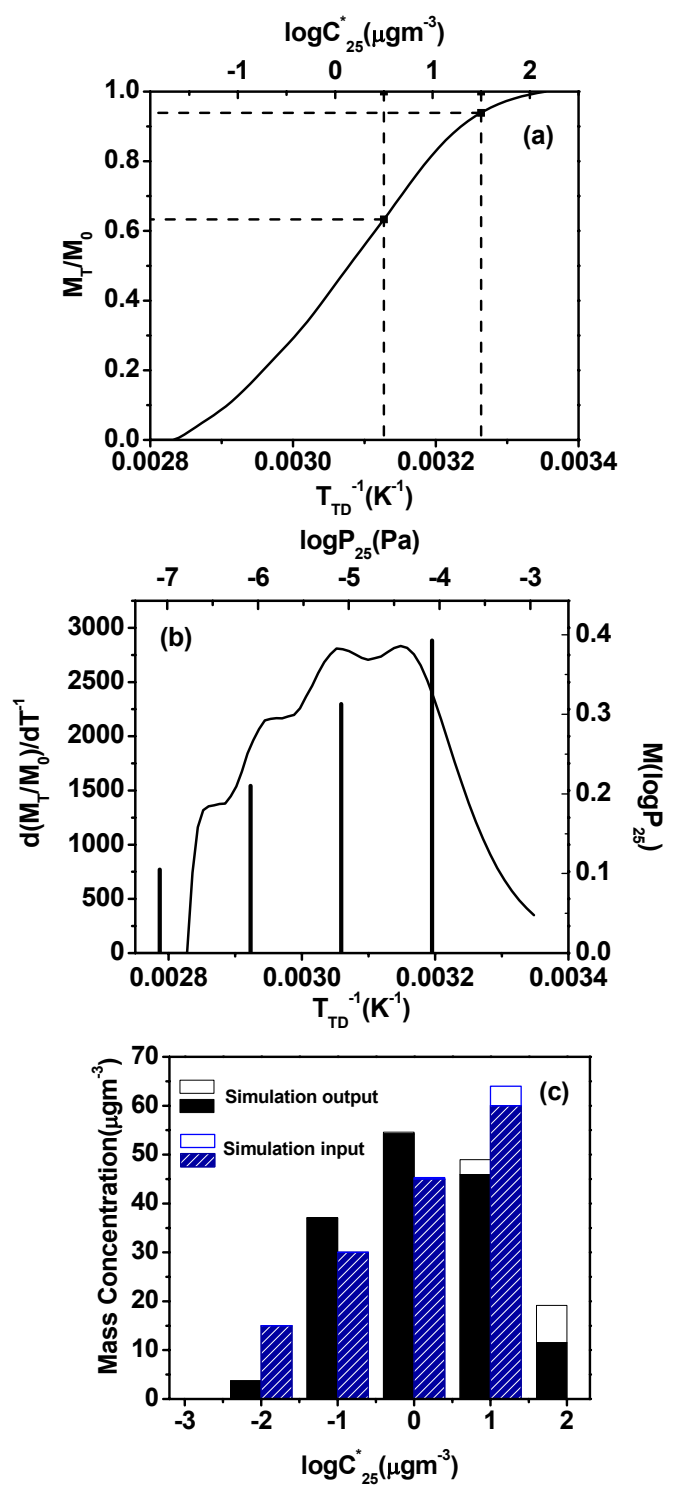

Fig. 7. Calculation of volatility distributions from the TD vaporization profile. (a) Simulated TD vaporization profile for a mixture of 4 compounds with saturation concentrations of $10^{-2}, 10^{-1}$, $10^{0}$, and $10^{1} \mu \mathrm{g} \mathrm{m}^{-3}$ at $25^{\circ} \mathrm{C}$. The $\log P_{25}$ distribution, $M\left(\log P_{25}\right)$, shown on the right axis in (b) is calculated by taking the derivative of $M_{T} / M_{0}$ with respect to $T_{\mathrm{TD}}^{-1}$ (shown on the left axis), converting the $\mathrm{x}$-axis from $T_{\mathrm{TD}}$ to $\log P_{25}$ using Eq. (1), and dividing $\mathrm{d}\left(M_{T} / M_{0}\right) / d\left(T_{\mathrm{TD}}^{-1}\right)$ by the slope in Eq. (1). The vertical bars in (b) indicate the vapor pressures and mass fractions of the compounds used as input for the simulation. The mass fractions of the particle mass concentration belonging to each order of magnitude $C_{25}^{*}$ bin, necessary for the volatility basis set analysis (c) are calculated by taking the difference between $M_{T} / M_{0}$ at the edges of the bin; the dashed lines in (a) indicate those values for the $C_{25}^{*}=10^{1} \mathrm{bin}$. Solid and open areas of the bars indicate particle phase and gas phase material, respectively. The distribution shown by solid bars in (c) was calculated from the curve in (a) by this procedure, and the distribution shown by the patterned bars in (c) was used as input for the simulation. 
distribution and the distribution calculated from the TD vaporization profile are apparent, and will be discussed in detail below in the context of the binned $\log C_{25}^{*}$ distribution.

\subsection{Volatility basis set analysis}

A volatility distribution of the type used by Donahue et al. (2006), showing the concentration and gas-particle partitioning of aerosol components as a function of $C_{25}^{*}$, the saturation concentration at $25^{\circ} \mathrm{C}$, and divided into bins based on $\log C_{25}^{*}$ (spaced, for example, by one order of magnitude in $C_{25}^{*}$ ), can also be estimated from the TD vaporization profile. In contrast to the vapor pressure distribution described above, which shows only the concentration of condensed phase material, this volatility distribution also includes the concentration of gas phase material inferred using partitioning theory.

The procedure for converting the TD vaporization profile to the $C_{25}^{*}$ distribution is illustrated in Fig. 7a and c. The fraction of a mixture (or single compound) vaporizing between any two temperatures is simply equal to the difference in $M_{T} / M_{0}$ evaluated at those temperatures; therefore the mass fraction $f_{i}$ of the particle-phase material in a mixture belonging in each $\log C_{25}^{*}$ bin can be calculated in this manner from the TD vaporization profile. First, it is necessary to determine the thermodenuder temperatures corresponding to the edges of each $\log C_{25}^{*}$ bin. For an ideal mixture, the saturation concentration of a compound in $\mu \mathrm{g} \mathrm{m}^{-3}$ is given by

$\left.C^{*}=M W P^{\circ} 10^{6} / R T\right)$

where $M W$ and $P^{\circ}$ are the molecular weight in $\mathrm{g} \mathrm{mol}^{-1}$ and partial vapor pressure in $\mathrm{Pa}$ of the compound, $R$ is the gas constant in $\mathrm{J} \mathrm{K}^{-1} \mathrm{~mol}^{-1}$, and $T$ is the temperature in $\mathrm{K}$. Combining Eq. (1) with Eq. (6) evaluated at $25^{\circ} \mathrm{C}$ gives

$T_{\mathrm{TD}}^{-1}\left(\mathrm{~K}^{-1}\right)=\left\{\log C_{25}^{*}+23.61+\log [(R \times 298.15 \mathrm{~K}) / M W]\right\} / 8171(7)$

Here, as in the calculation of $M\left(\log P_{25}\right), T_{50}$ in Eq. (1) has been replaced with $T_{\mathrm{TD}}$, and $P_{25}$ has been replaced with $P^{\circ}$. In general, the identity of the compounds in the mixture being analyzed is not known, and the basis set can be considered to represent a set of hypothetical compounds, with saturation concentrations spaced by a factor of 10 in $C_{25}^{*}$. MW may be replaced with an estimated average molecular weight, or it may be treated as a function of $C^{*}$, with the hypothetical compound in each $\log C_{25}^{*}$ bin having its own molecular weight $M W_{i}$. If a different molecular weight is used for each $\log C_{25}^{*}$ bin, $f_{i}$ must be adjusted using the Jacobian due to the non-linear dependence of $\log C_{25}^{*}$ on $T_{\mathrm{TD}}$. The calculation of $f_{i}$ is illustrated in Fig. 7a for the $\log C_{25}^{*}=1$ bin, with the dashed lines indicating the values of $T_{\mathrm{TD}}^{-1}, \log C_{25}^{*}$, and $M_{T} / M_{0}$ at the edges of the bin. For the experimental datasets analyzed in this study, $M_{T} / M_{0}$ at the temperatures corresponding to the boundaries of each $\log C_{25}^{*}$ bin were found by linear interpolation, and a calculated or estimated average molecular weight was used.
Next, it is necessary to determine $C_{p}$ and $C_{g}$, the particleand gas-phase concentrations for the material in each $\log C_{25}^{*}$ bin. From partitioning theory (Donahue et al., 2006; Pankow, 1994a)

$C_{p, i} / C_{g, i}=C_{\mathrm{OA}} / C_{i}^{*}$

where $C_{\mathrm{OA}}$ is the total concentration of particle-phase organic matter, which must be measured in a separate experiment or estimated. $C_{p, i}$ is equal to the fraction of the total $C_{\mathrm{OA}}$ which belongs in bin $i$, i.e.,

$C_{p, i}=f_{i} C_{\mathrm{OA}}$

Combining Eqs. (8) and (9) gives

$C_{g, i}=f_{i} C_{i}^{*}$

The values of $C_{p, i}$ are represented by the solid areas of the bars in Fig. 7c, and the values of $C_{g, i}$ are represented by the open areas.

Gas-particle partitioning of aerosol prior to entering the TD will be determined by the ambient temperature; therefore if TD experiments are performed at an ambient temperature other than $25^{\circ} \mathrm{C}$ Eqs. (9) and (10) will give the particle and gas phase concentrations for compound $i$ at that ambient temperature, and $C_{i}^{*}$ in Eq. (10) must be the saturation concentration for compound $i$ at ambient temperature for the results to be valid. Therefore, the procedure is to first calculate the distribution at ambient temperature, then calculate the partitioning for the resulting total mass concentrations in each bin at $25^{\circ} \mathrm{C}$. To simplify the eventual conversion from the distribution at ambient temperature to one at $25^{\circ} \mathrm{C}$, it is simplest to calculate $f_{i}$ for bins corresponding to the $C_{i 25}^{*}$ basis set, that is, to keep the same set of hypothetical compounds. The $\log P_{25}$ vs. $T_{50}^{-1}$ calibration will still be valid, and $f_{i}$ and $C_{p, i}$ can be calculated as described above. The $C_{i}^{*}$ values at ambient temperature that correspond to the $C_{i 25}^{*}$ basis set values can be calculated using the Clausius-Clapeyron equation (Eq. 5) and the fact that $C^{*}$ is proportional to vapor pressure (Eq. 6), which combine to give

$C_{T_{\mathrm{amb}}}^{*}=\left(298.15 \mathrm{~K} / T_{\mathrm{amb}}\right) C_{25}^{*} \exp \left[-\Delta H_{\text {vap }} / R\left(1 / T_{\mathrm{amb}}-1 / 298.15 \mathrm{~K}\right)\right](11)$

where $T_{\mathrm{amb}}$ is the ambient temperature in K. In Fig. 7a this would be equivalent to changing the $\log C_{25}^{*}$ axis to a $\log C_{T_{\mathrm{amb}}}^{*}$ axis, but keeping the dashed lines defining the bin edges fixed. Donahue et al. (2006) suggest using values of $\Delta H_{\text {vap }}$ that decrease with increasing $C^{*}$, with $\Delta H_{\mathrm{vap}}=100 \mathrm{~kJ} / \mathrm{mol}$ for $C^{*}=1 \mu \mathrm{g} \mathrm{m}^{-3}$ at $300 \mathrm{~K}$, and an increment of $-5.8 \mathrm{~kJ} \mathrm{~mol}^{-1}$ for each successive $\log C^{*}$ bin, when the bins are separated by a factor of 10 in $C^{*}$. Once $C_{p, i}$ and $C_{g, i}$ for each $\log C_{T, \text { amb }}^{*}$ bin have been calculated using Eqs. (9) and (10), the total concentration of organic material for each $\log C_{T, \text { amb }}^{*}$ bin, $C_{\text {tot, } i}$ is known, and the partitioning at $25^{\circ} \mathrm{C}$ can be predicted. By definition,

$C_{\mathrm{OA}}=\Sigma C_{p, i}$ 
and by noting that $C_{\mathrm{tot}, i}=C_{p, i}+C_{g, i}$ and rearranging Eq. (8), we get

$C_{p, i}=C_{\mathrm{OA}} C_{\mathrm{tot}, i} /\left(C_{i}^{*}+C_{\mathrm{OA}}\right)$

Equations (12) and (13) can be iteratively solved to find the volatility basis set distribution at $25^{\circ} \mathrm{C}$ (Donahue et al., 2006). Volatility information from the TD extends up to the $C^{*}$ corresponding to the ambient temperature. If the calibration is done at a mass concentration close to the concentration of the aerosol being sampled, this should be essentially $C_{\mathrm{OA}}$.

Several factors that influence the measured volatility distributions (either in the volatility basis set framework or in the form of a vapor pressure distribution) can be seen by comparing the input distribution ("simulation input") and the distribution calculated from the simulated TD vaporization profile ("simulation output") in Fig. 7c. The width of the TD vaporization profile, even for a pure compound, will broaden the measured distribution. For typical TD vaporization profiles of pure standards, $M_{T} / M_{0} 12^{\circ} \mathrm{C}$ above and below $T_{50}$ is $\sim 0.9$ and 0.1 , respectively. The broadening in the calculated $C^{*}$ distribution increases with decreasing $T_{50}$. For $T_{50}=40$ ${ }^{\circ} \mathrm{C}, \sim 10 \%$ of the mass will be calculated to be at a $C^{*} 1$ order of magnitude higher, and $\sim 10 \% 1$ order of magnitude lower, than the true $C^{*}$. For $T_{50}=170{ }^{\circ} \mathrm{C}$, the difference is reduced to about 0.5 orders of magnitude. The output distribution in Fig. $7 \mathrm{c}$ shows significant intensity in the $10^{2} \mu \mathrm{g} \mathrm{m}^{-3}$ bin, where there is none for the input distribution, due to this effect.

In addition, there are factors which bias the TD vaporization profile of each component in a mixture, that is, the plot of the mass of that component in the particle phase divided by its initial mass vs. $T_{\mathrm{TD}}$, relative to the TD vaporization profile of particles of the pure compound at the same initial particle size and number concentration. Since the total TD vaporization profile for a mixture calculated from the TI signal is essentially the mass fraction weighted average of the component profiles, this is an appropriate comparison. Differences in the partial vapor pressure are one such factor. Initially, if we assume ideal behavior, the partial vapor pressure of a component is equal to its vapor pressure in a pure particle multiplied by its initial mole fraction in the mixture. However, the initial rate of change in the mass fraction remaining of that component with time will be roughly the same as that for a pure particle, since the initial mass of that component (its mass fraction multiplied by the total mass) and its evaporation rate are reduced by a similar factor. As material evaporates from the particle, however, the mole fraction, and therefore the partial vapor pressure, will be reduced for more volatile components and increased for less volatile components, relative to that in the mixed particle initially. This causes more volatile components to tail toward lower volatility, and less volatile components to be shifted toward higher volatility, causing a bias toward the center of the distribution and a shift toward higher volatility of the low volatility cutoff. At the same time, the particle size at a given point in the TD vaporization profile for a specific component is affected as the particle composition is changed by evaporation. For high volatility components, the evaporating particle will be larger for a mixture than for a pure particle due to the remaining low volatility material, and for low volatility components, it will be smaller since the particle has already shrunk due to the removal of higher volatility species by the time the low volatility species are evaporating significantly. This increases or decreases, respectively, the surface area available for evaporation for high and low volatility components (since we are comparing vaporization profiles for the same number density of particles), causing a bias that is opposite to, but less than that of the partial vapor pressure (the actual effect of particle surface area on the rate of mass lost from the particle is particle size-dependent, but it is less important than the effect of the changing partial vapor pressure in either the continuum model or the free molecule model). In Fig. 7c, the combined effect of these factors is less obvious at the high volatility end of the distribution, but can be seen clearly at the low volatility end, where the simulation output shows much less mass in the $10^{-2} \mu \mathrm{g} \mathrm{m}^{-3}$ bin than the input distribution does.

Of the factors discussed above, the broadening due to the TD vaporization profile width is probably the most significant. It will tend to be most obvious at the high vapor pressure end of the distribution, where it is greater and there are no significant opposing effects, and may lead to large errors in the total mass assigned to high $C^{*}$ bins, since the $C_{g} / C_{p}$ ratio is highest there. While there is no fool-proof way to correct for this, intensity in bins at the high $C^{*}$ end of the distribution should be treated with caution, especially when the intensity in the bins immediately to lower $C^{*}$ is much greater.

It should be noted that the factors discussed above - the broadening due to the TD vaporization profile width and the fact that the measured vapor pressure for a component in a mixture depends on the mass fraction as well as the actual vapor pressure - imply that the true volatility distribution is not uniquely defined by the measured distribution. For example, all else being equal, a distribution with $10 \mu \mathrm{g} \mathrm{m}^{-3}$ in the $C^{*}=10^{-1} \mu \mathrm{g} \mathrm{m}^{-3}$ bin and nothing in the higher volatility bins will give roughly the same measured distribution as one with $9 \mu \mathrm{g} \mathrm{m}^{-3}$ in the $C^{*}=10^{-1} \mu \mathrm{g} \mathrm{m}^{-3}$ bin and $1 \mu \mathrm{g} \mathrm{m}^{-3}$ in the $C^{*}=10^{0}$ bin due to broadening. Similarly, a mass fraction of $5 \%$ in a bin at the low volatility end of the distribution can give the same intensity in the next-to-lowest volatility bin as a mass fraction of $10 \%$ in the next-to-lowest volatility bin because a lower mass fraction at this end of the distribution is shifted more to the higher volatility side. These are extreme examples, but these factors should be borne in mind when interpreting measured volatility distributions. A similar issue has been discussed recently by Stanier et al. (2008) with respect to the parameterization of volatility data from chamber experiments. 


\subsection{Simple mixture}

The use of the calibration curve for estimating vapor pressure distributions was tested on a simple mixture consisting of compounds with known vapor pressures. Particles consisted of a mixture of oleic acid and $\mathrm{C}_{15}, \mathrm{C}_{16}, \mathrm{C}_{18}$, and $\mathrm{C}_{20}$ saturated monocarboxylic acids in a 4:1:1:1:1 mole ratio. This mixture, containing compounds with similar structures and a large fraction of liquid oleic acid, was chosen in order to increase the likelihood of the particles being a single liquid phase. The particles were $200 \mathrm{~nm}$ in diameter and the total mass concentration was $100-150 \mu \mathrm{g} \mathrm{m}^{-3}$, similar to the conditions used to generate the calibration curve. In one experiment, mass fragments characteristic of each of the acids were monitored in SIM mode, and in another, full spectral scans were recorded and the TI signal computed.

The vapor pressure distributions calculated from the characteristic mass fragments, the TI signal, and the mass fraction weighted average of the characteristic fragment signals are shown in Fig. 8a. The individual fragment distributions are scaled by a factor of $1 / 2$ for clarity. The top axis shows the $\log P_{25}$ scale calculated using Eq. (1), and the vertical lines indicate the $\log P_{25}$ values for the pure individual compounds from the literature, which are listed in Table 2. The $\mathrm{C}_{15}$ and $\mathrm{C}_{16}$ monoacid profiles exhibit the expected ordering, with the $\mathrm{C}_{16}$ compound evaporating at a slightly higher temperature than the $\mathrm{C}_{15}$, and the peaks in their signals agree reasonably well with the literature $P_{25}$ values. The SIM curves are wider than those typically observed for pure compounds, with the curve for the $\mathrm{C}_{15}$ monoacid tailing toward higher temperature and the other curves broadened in both directions. Nonetheless, on the low temperature side of the curves the TI or sum of SIM signals provide good approximations of the vapor pressure distribution. The curves for the less volatile components do not follow the behavior expected from their vapor pressures; rather, all three peak at essentially the same temperature, corresponding to a $P_{25}$ value close to that of oleic acid. Similar volatility behavior has been seen previously in monoacid and diacid mixtures containing oleic acid (Chattopadhyay, 2004), and suggests non-ideal behavior of the mixture. The similarity of the TD vaporization profiles of oleic acid and the $\mathrm{C}_{18}$ and $\mathrm{C}_{20}$ monoacids suggests that they may form a separate phase, excluding the other two components, with oleic acid acting as a matrix which determines the volatility behavior of the phase. The TD vaporization profiles of the $\mathrm{C}_{18}$ and $\mathrm{C}_{20}$ monoacids in this mixture reflect their effective vapor pressures in the mixture in the temperature range in which they evaporate significantly. The effective vapor pressure of a component in a mixture is of interest in itself, since it determines the gas-particle partitioning of the component as long as the mixture in which it is present is fairly constant. Between $25^{\circ} \mathrm{C}$ and this temperature range, the organization of the mixture among condensed phases may change, so it is not clear whether the effective $P_{25}$ values for oleic acid and the $\mathrm{C}_{18}$ and $\mathrm{C}_{20}$ monoacids in

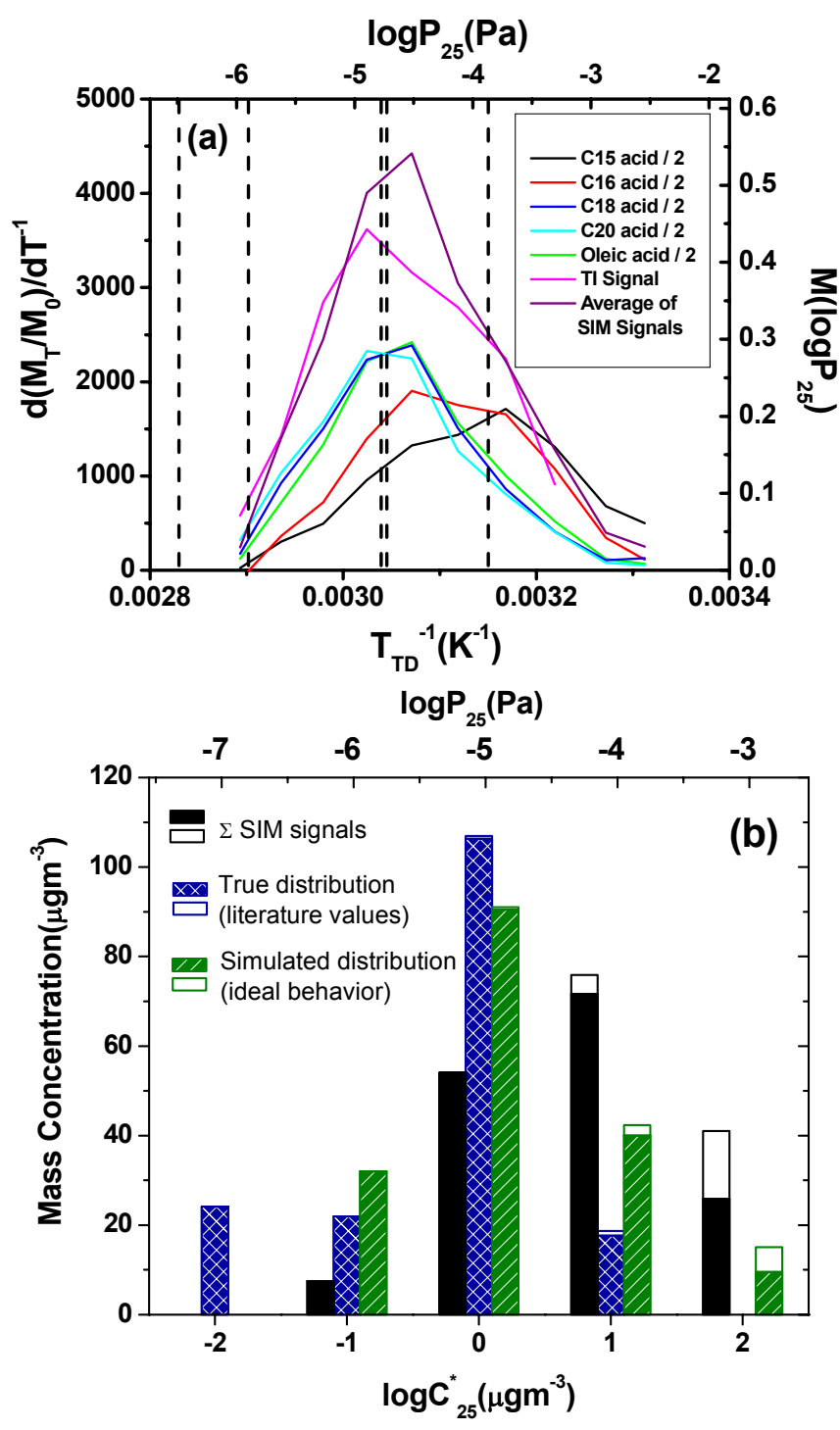

Fig. 8. (a) $\log P_{25}$ distribution for a mixture of $\mathrm{C}_{15}, \mathrm{C}_{16}, \mathrm{C}_{18}$, and $\mathrm{C}_{20}$ monoacids and oleic acid in mole ratios of 1:1:1:1:4. The fragments monitored in SIM mode for the individual components in the mixture were: pentadecanoic acid, $\mathrm{m} / \mathrm{z} 242$; hexadecanoic acid, $\mathrm{m} / \mathrm{z}, 256$; octadecanoic acid, $\mathrm{m} / \mathrm{z} 2284$; eicosanoic acid, $\mathrm{m} / \mathrm{z} 312$; oleic acid, $m / z 264$. For clarity, the curves for the individual SIM profiles were scaled by a factor of $1 / 2$. The vertical lines are the averaged literature $P_{25}$ values shown in Table 2 for each compound. (b) Volatility distribution for the mixture of $\mathrm{C}_{15}, \mathrm{C}_{16}, \mathrm{C}_{18}$, and $\mathrm{C}_{20}$ monoacids and oleic acid showing calculated gas-particle partitioning. Solid and open areas of the bars indicate particle phase and gas phase material, respectively. The experimental distribution was calculated from the mass fraction weighted average of the SIM profiles. The true distribution was calculated from the mass fractions of the components in the mixture and the literature values of $P_{25}$ shown in (a). 
this mixture can be calculated from the calibration (Eq. 1). The much more complex mixtures typically found in ambient aerosol are less likely to show such behavior, since they are more likely to consist of a complex mixture in which no single compound is present in such a high concentration that it acts as a matrix.

In Fig. 8b, the values of $C_{p}$ (solid area) and $C_{g}$ (open area) calculated from the weighted sum of fragment signals, binned by order of magnitude in $C^{*}$, are shown, along with the true distribution calculated from the mass fractions of components in the mixture and literature values of $P_{25}$, and the distribution recovered by simulating the TI signal for the mixture with a continuum model, using the true distribution as input. As in Fig. 7, a separate calibration was used to calculate $P_{25}$ and $C^{*}$ for the simulation output, so that differences between the distributions calculated from the experimental vaporization profile and the simulation output more closely reflect differences between the real volatility behavior of the mixture and simulated ideal behavior, rather than biases in the simulation. $C^{*}$ in this plot is calculated from $P_{25}$ using an averaged molecular weight and assuming ideal behavior. The experimental distribution shows significant intensity in the $10^{2} \mu \mathrm{g} \mathrm{m}^{-3}$ bin, where there is none for the true distribution. This is consistent with the behavior seen for the hypothetical distribution shown in Fig. 7, and the fact that the simulation output shows the same behavior, although to a somewhat lesser extent, supports the conclusion that this is due to the finite width of the vaporization profile for the $\mathrm{C}_{15}$ acid. The low volatility side of the distribution for both the experimental distribution and the simulation output is biased toward higher volatility - neither shows intensity in the $10^{-2} \mu \mathrm{g} \mathrm{m}^{-2}$ bin, where there is significant intensity in the true distribution. Overall, the simulation output is shifted to lower volatility than the experimental distribution by $\sim 0.5$ orders of magnitude in $C^{*}$. It is not clear whether this is due to a bias in literature vapor pressures or other factors. The non-ideal behavior described above, in which the three lowest-volatility components vaporize at essentially the same temperature, may contribute to this difference, but it may only have the effect of smoothing the low volatility side of the distribution. However, considering uncertainties in the literature values for $P_{25}$ (values shown in Table 1 for individual components in this mixture vary by a factor of $\sim 2-5$ ), the agreement between the experimental distribution and the simulation output is fairly good.

\subsection{Secondary organic aerosol}

Chamber-generated SOA, though less complex than ambient aerosol, is still much more complex than the monoacid mixture discussed above. The volatility of SOA formed from the reaction of pentadecane with $\mathrm{OH}$ radicals in the presence of $\mathrm{NO}_{\mathrm{x}}$ has been studied previously in this laboratory (Lim and Ziemann, 2005), using TPTD. Two fairly well-defined peaks and a shoulder were seen in the desorption profile, which

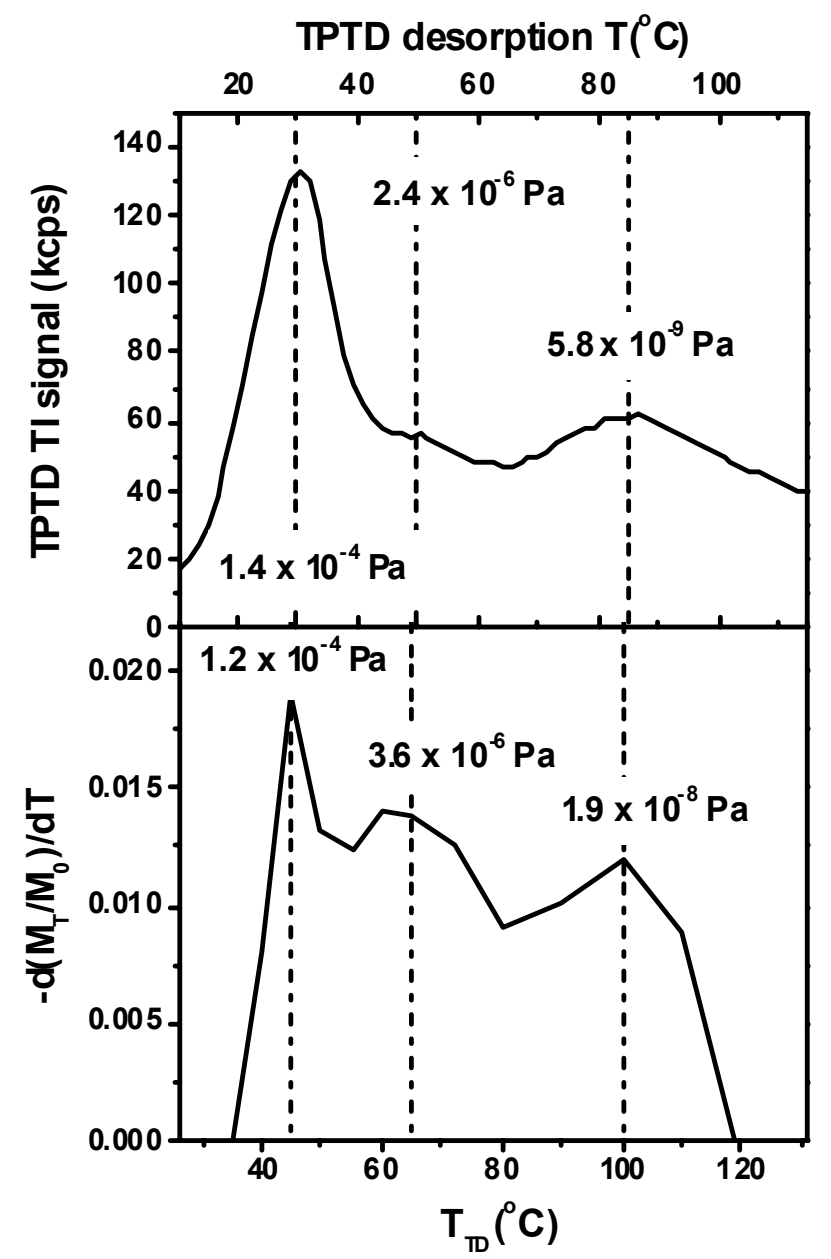

Fig. 9. (top) TPTD desorption profile for laboratory-generated SOA formed from the reaction of pentadecane with $\mathrm{OH}$ radicals (Lim and Ziemann, 2005) and (bottom) negative of the derivative of the TD vaporization profile with respect to $T_{\mathrm{TD}}$.

makes this a particularly good system for evaluating the TD method.

A calibration of $\log P_{25}$ vs. $T_{\text {des }}^{-1}$ for the TPTD technique was determined using a series of saturated mono- and dicarboxylic acids, with $P_{25}$ determined from the singlecompound desorption profiles (Chattopadhyay and Ziemann, 2005), and the equation of the least squares fit to all the data points was

$\log P_{25}(\mathrm{~Pa})=8637 T_{\text {des }}^{-1}-32.35$

Note that the slope of this equation is similar to that in the TD calibration curve (Eq. 1). The TPTD desorption profile and the temperature derivative of the TD vaporization profile for SOA formed from the pentadecane $+\mathrm{OH}$ reaction are shown in the top and bottom panels of Fig. 9, respectively. The temperature axes are offset by $16^{\circ} \mathrm{C}$ for ease of comparison. The agreement in the positions of the main features, after allowing for an offset of $16^{\circ} \mathrm{C}$, and vapor 
pressures calculated from the respective calibrations has been pointed out above, and illustrated in Figs. 4 and 5. In Fig. 9, the positions of the main features in the profiles are marked by dashed vertical lines. The features in both profiles are marked with the $P_{25}$ values calculated from the calibration curves. The values of $P_{25}$ measured by the two techniques are within a factor of $\sim 3$ for each peak, which is well within the estimated uncertainty of one order of magnitude in calculating $P_{25}$ (it should be noted that the values of $P_{25}$ and $C^{*}$ in Figs. 9 and 10 extend below the range covered by the calibration by about 3 orders of magnitude, and the uncertainty at these lower volatilities, as discussed in Sect. 3.2, is necessarily greater than it is within the calibration range). There are significant differences in the relative intensities of the various peaks that may reflect differences between the techniques or real differences in the composition of the aerosol, which may vary somewhat between experiments. Overall, the consistency between the two methods is quite good.

The $\log P_{25}$ distribution and binned $C^{*}$ distribution calculated from the TD vaporization profile are shown in Fig. 10a and $\mathrm{b}$. The two major features in the $\log P_{25}$ distribution, centered at $\log P_{25}=-4$ and $-8\left(\log C^{*} \cong 1\right.$ and -3$)$, are still visible in the $\log C^{*}$ distribution after binning. The small intensity in the $10^{2} \mu \mathrm{g} \mathrm{m}^{-3}$ bin is probably due to the broadening of the signal from material in the $10^{1} \mu \mathrm{g} \mathrm{m}^{-3} \mathrm{bin}$, in which the intensity is much higher. The intensity in the $10^{1} \mu \mathrm{g} \mathrm{m}^{-3}$ bin, however, is probably a good indication of the true amount of material in that bin.

The TD vaporization profile for this SOA sample was measured at a particle mass concentration of $\sim 150 \mu \mathrm{g} \mathrm{m}^{-3}$, which is much higher than typical ambient SOA concentrations. The partitioning by volatility bin predicted for this SOA sample after 10-fold dilution, found by solving Eqs. (12) and (13) iteratively for $C_{\mathrm{OA}}$ and $C_{p, i}$, is shown in Fig. 10c. The particle mass concentration, $C_{\mathrm{OA}}$, is reduced from $150 \mu \mathrm{g} \mathrm{m}^{-3}$ to $13.4 \mu \mathrm{g} \mathrm{m}^{-3}$ (a slightly greater than 10 fold decrease, due to the greater fraction of mass in the gas phase at higher dilution), and the increase in the fraction of material in the gas phase for $C^{*}>10^{-1} \mu \mathrm{g} \mathrm{m}^{-3}$ is evident.

\subsection{Mass spectral analysis}

The composition of aerosol as a function of volatility is of considerable interest in learning about how the volatility distribution changes with photochemical aging, and it may also enhance the separation of OA sources/components for component analysis methods that identify sources and components by exploiting mass spectral differences (Zhang et al., 2005; Ulbrich et al., 2008). Differences in the mass spectrum as the composition of the vaporized fraction changes may also yield information on the composition of the different volatility fractions (Huffman et al., 2009). In the case of the SOA generated from the pentadecane $+\mathrm{OH}$ reaction, the presence of well-defined peaks in the $\log P_{25}$ distribution in Fig. 10a suggests the possibility of comparing the mass

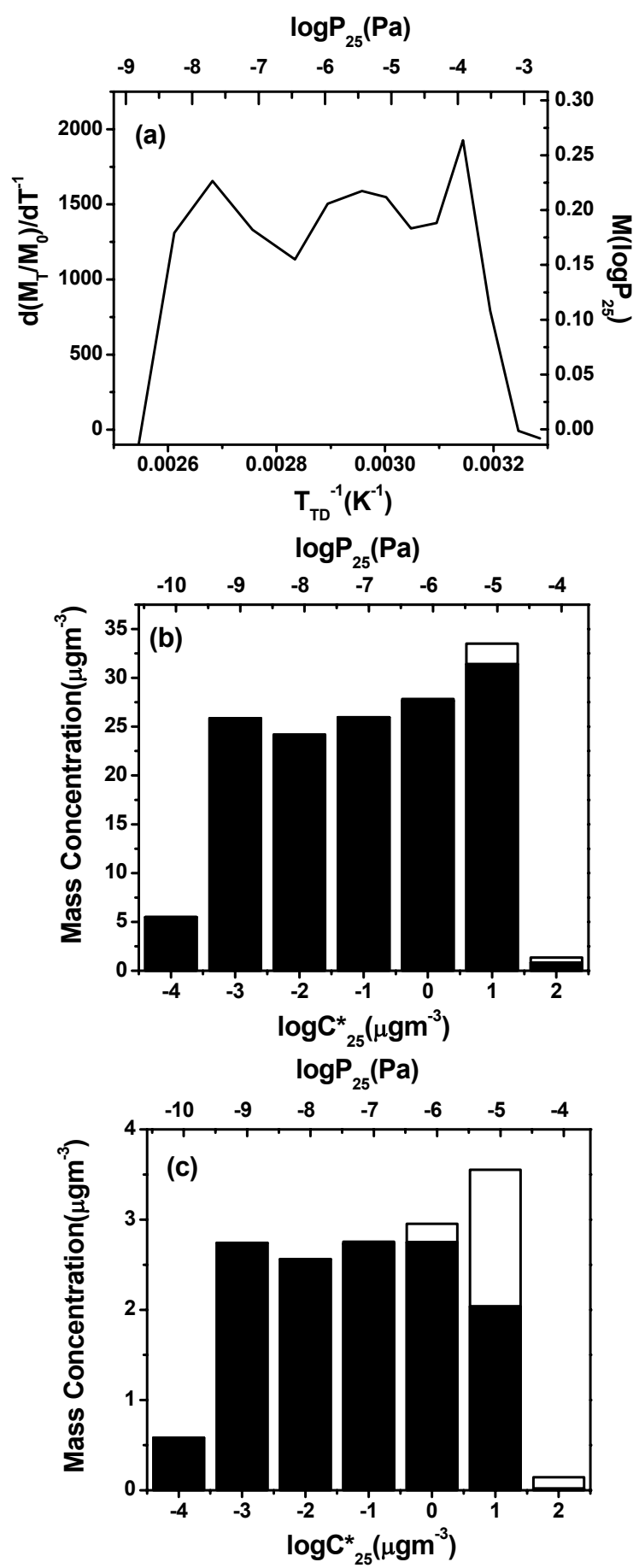

Fig. 10. (a) $\log P_{25}$ distribution and (b) Volatility basis set distribution for laboratory-generated SOA formed from the reaction of pentadecane with $\mathrm{OH}$ radicals. (c) Calculated gas-particle partitioning for the same aerosol after 10-fold dilution. Solid and open areas of the bars in (b) and (c) indicate particle phase and gas phase material, respectively. The particle mass concentration was $\sim 150 \mu \mathrm{g} \mathrm{m}^{-3}$. 


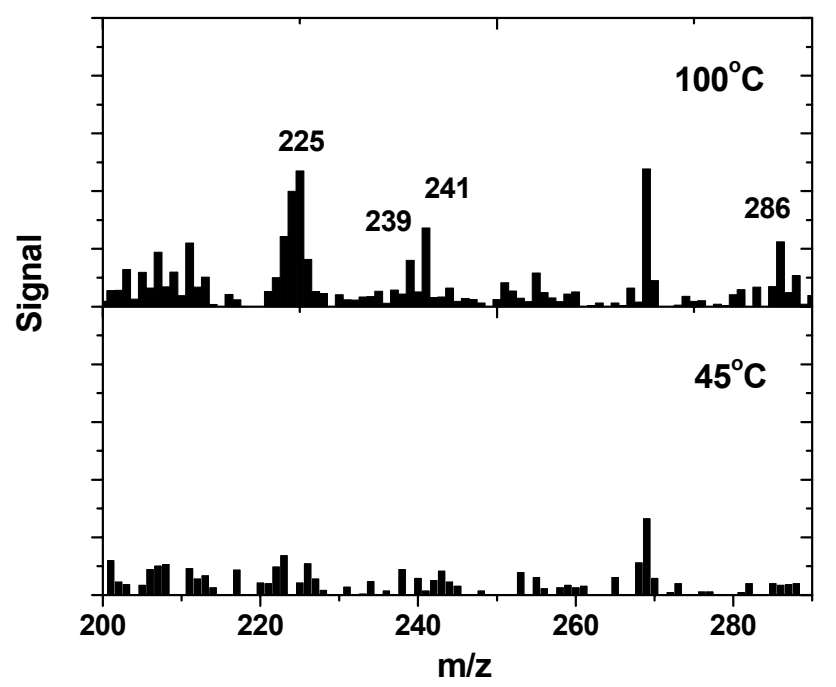

Fig. 11. Mass spectra of material volatilized at $45^{\circ} \mathrm{C}$ and $100^{\circ} \mathrm{C}$ from SOA formed from the reaction of pentadecane with $\mathrm{OH}$ radicals. The spectra were calculated by subtracting the mass spectrum of aerosol sampled after passing through the TD from that sampled after passing through the TD bypass tube.

spectra obtained at the temperatures corresponding to these peaks. Figure 11 shows mass spectra of the vaporized fraction (that is, the difference between the spectra measured when the aerosol is sampled at the exits of the bypass tube and the TD, respectively) at $T_{\mathrm{TD}}=45$ and $100^{\circ} \mathrm{C}$, corresponding to $\log P_{25}=-3.9$ and -7.7 , respectively, the positions of the two most prominent peaks in the vapor pressure distribution. Peaks at $m / z 225,239,241$, and 286, which are absent at $45^{\circ} \mathrm{C}$, can be seen at $100^{\circ} \mathrm{C}$. This is consistent with the mass spectra obtained at the corresponding peaks in the TPTD experiment (Lim and Ziemann, 2005), and shows that it is possible to obtain information on the chemical composition of aerosol as a function of volatility using this technique.

\section{Conclusions}

This paper describes the development and evaluation of a technique that couples a thermodenuder with a particle beam mass spectrometer to determine the vapor pressures of organic aerosol components. An important feature of this technique is its simplicity, which allows the vapor pressure distribution for a complex mixture such as that found in ambient aerosols to be estimated from a $M_{T} / M_{0}$ vs. $T$ measurement and a single calibration curve. The empirical approach avoids complex modeling and the need to make assumptions about numerous unknown properties of the aerosol and physical parameters of the system. While ignoring these complex problems does not make them go away, the range of uncertainties that are likely to be encountered in the application of this method can be explored by studying realistic systems.
This has been attempted here by using simulations and by analyzing a simple, five-component mixture and a more complex chamber-generated SOA. The results suggest that for the range of particle sizes and mass concentrations typical for the atmosphere and laboratory studies, vapor pressures of aerosol components can probably be estimated to within about one order of magnitude, which is accurate enough to be of considerable use in aerosol volatility studies, and is a vast improvement over the estimates currently used in atmospheric models (Huffman et al., 2009). Volatility distributions using the volatility basis set approach of Donahue et al. (2006) can be estimated easily from the TD vaporization data, implying that the TD-AMS will be of use in modeling based on this type of volatility analysis. From the experiments on simple and complex (SOA) mixtures, it is also evident that some separation of compounds by volatility can be achieved, and that it is possible to obtain information on aerosol composition as a function of volatility. This may be of considerable interest for the development of methods for deconvoluting AMS spectra of different organic aerosol classes (Zhang et al., 2005), which are important for advancing the analysis and understanding of organic aerosols, and for studying the evolution of aerosol volatility with photochemical aging.

\section{Appendix A}

\section{Symbols and abbreviations}

\begin{tabular}{|c|c|}
\hline AMS & Aerodyne Aerosol Mass Spectrometer \\
\hline$C^{*}$ & saturation concentration \\
\hline$C_{25}^{*}$ & saturation concentration at $25^{\circ} \mathrm{C}$ \\
\hline$C_{i}^{*}$ & saturation concentration for bin $i$ \\
\hline$C_{T, \mathrm{amb}}^{*}$ & saturation concentration at ambient temperature \\
\hline$C_{g, i}$ & concentration of gas-phase material in bin $i$ \\
\hline$C_{\mathrm{OA}}$ & total concentration of organic particulate material \\
\hline$C_{p, i}$ & concentration of particle-phase material in bin $i$ \\
\hline$C_{\text {tot }, i}$ & total concentration of material in bin $i$ \\
\hline DMA & differential mobility analyzer \\
\hline DOS & dioctyl sebacate \\
\hline$D_{v}$ & $\begin{array}{l}\text { gas-phase diffusion coefficient of evaporating } \\
\text { compound }\end{array}$ \\
\hline$d_{p}$ & particle diameter \\
\hline$d_{p, 0}$ & initial particle diameter at $t=0$ \\
\hline $\begin{array}{l}f_{i} \\
\mathrm{HOA}\end{array}$ & $\begin{array}{l}\text { fraction of total organic particle-phase mass in bin } i \\
\text { hydrocarbon-like organic aerosol }\end{array}$ \\
\hline$M\left(\log P_{25}\right)$ & log-scale mass vs. vapor pressure distribution \\
\hline$M_{0}$ & $\begin{array}{l}\text { the aerosol mass concentration measured at the } \\
\text { exit of the TD bypass tube }\end{array}$ \\
\hline$M_{T}$ & $\begin{array}{l}\text { the aerosol mass concentration measured at the exit of } \\
\text { the TD when set at temperature } T\end{array}$ \\
\hline$M W$ & molecular weight \\
\hline $\mathrm{OA}$ & organic aerosol \\
\hline OOA & oxygenated organic aerosol \\
\hline$P^{\circ}$ & partial vapor pressure \\
\hline$P_{25}$ & saturation vapor pressure at $25^{\circ} \mathrm{C}$ \\
\hline$P_{\infty}$ & partial pressure of evaporating compound \\
\hline $\begin{array}{l}P_{d} \\
\mathrm{POA}\end{array}$ & $\begin{array}{l}\text { vapor pressure at surface of particle with diameter } d \\
\text { primary organic aerosol }\end{array}$ \\
\hline
\end{tabular}




\begin{tabular}{|c|c|}
\hline$R$ & gas constant $\left(=8.314 \mathrm{JK}^{-1} \mathrm{~mol}^{-1}\right)$ \\
\hline SIM & single ion monitoring \\
\hline SOA & secondary organic aerosol \\
\hline$t$ & time \\
\hline$t_{r}$ & residence time in TD \\
\hline$T$ & temperature \\
\hline$T_{50}$ & $\begin{array}{l}\text { temperature at which } 50 \% \text { of the OA mass } \\
\text { has evaporated }\end{array}$ \\
\hline$T_{\mathrm{amb}}$ & ambient temperature \\
\hline TD & thermodenuder \\
\hline TDPBMS & thermal desorption particle beam mass spectrometer \\
\hline$T_{\mathrm{des}}$ & temperature of the peak in the TPTD desorption profile \\
\hline TI & total ion \\
\hline$T_{\text {infl }}$ & $\begin{array}{l}\text { inflection point temperature in the TD } \\
\text { vaporization profile }\end{array}$ \\
\hline TPTD & temperature programmed thermal desorption \\
\hline$T_{\mathrm{TD}}$ & $\begin{array}{l}\text { temperature of the TD heated section (set-point temper- } \\
\text { ature for experiments, uniform temperature for simula- } \\
\text { tions) }\end{array}$ \\
\hline$\alpha$ & evaporation coefficient \\
\hline$\Delta H_{\text {vap }}$ & heat of vaporization \\
\hline$\lambda$ & $\begin{array}{l}\text { mean free path of vapor molecule of evaporating } \\
\text { compound }\end{array}$ \\
\hline$\rho$ & $\begin{array}{l}\text { density of evaporating compound in the } \\
\text { condensed phase }\end{array}$ \\
\hline
\end{tabular}

Acknowledgements. This research was supported by the US Environmental Protection Agency, Office of Research and Development [Assistance Agreement RD-831080, Science to Achieve Results (STAR) grant]. While this research has been supported by the US Environmental Protection Agency, it has not been subjected to Agency review and, therefore, does not necessarily reflect the views of the Agency, and no official endorsement should be inferred.

Edited by: A. Wiedensohler

\section{References}

An, W. J., Pathak, R. K., Lee, B. H., and Pandis, S. N.: Aerosol volatility measurement using an improved thermodenuder: Application to secondary organic aerosol, J. Aerosol Sci., 38, 305314, doi:10.1016/j.jaerosci.2006.12.002, 2007.

Atkinson, R., Carter, W. P. L., Winer, A. M., and Pitts Jr., J. N.: An experimental protocol for the determination of $\mathrm{OH}$ radical rate constants with organics using methyl nitrite photolysis as an $\mathrm{OH}$ radical source, Air Pollut. Control Assoc., 31, 1090-1092, 1981.

Bilde, M., Svenningsson, B., Monster, J., and Rosenorn, T.: Evenodd alternation of evaporation rates and vapor pressures of C3C9 dicarboxylic acid aerosols, Environ. Sci. Technol., 37, 13711378, doi:10.1021/ES0201810, 2003.

Bondi, A.: Estimation of heat capacity of liquids, Ind. Eng. Chem. Fund., 5, 442-449, 1966.

Chattopadhyay, S.: Products and mechanism of secondary organic aerosol formation from reactions of n-alkanes with $\mathrm{OH}$ radicals in the presence of NOx, Ph.D. thesis, University of California, Riverside, 2004.

Chattopadhyay, S. and Ziemann, P. J.: Vapor pressures of substituted and unsubstituted monocarboxylic and dicarboxylic acids measured using an improved thermal desorption particle beam mass spectrometry method, Aerosol Sci. Technol., 39, 10851100, doi:10.1080/02786820500421547, 2005.
Crable, G. F. and Coggeshall, N. D.: Application of total ionization principles to mass spectrometric analysis, Anal. Chem., 30, 310313, 1958.

de Gouw, J. A., Middlebrook, A. M., Warneke, C., Goldan, P. D., Kuster, W. C., Roberts, J. M., Fehsenfeld, F. C., Worsnop, D. R., Canagaratna, M. R., Pszenny, A. A. P., Keene, W. C., Marchewka, M., Bertman, S. B., and Bates, T. S.: Budget of organic carbon in a polluted atmosphere: Results from the New England air quality study in 2002, J. Geophys. Res.-Atmos., 110, D16305, doi:10.1029/2004JD005623 2005.

Donahue, N. M., Robinson, A. L., Stanier, C. O., and Pandis, S. N.: Coupled partitioning, dilution, and chemical aging of semivolatile organics, Environ. Sci. Technol., 40, 2635-2643, doi:10.1021/ESO52297C, 2006.

Fuchs, N. A. and Sutugin, A. G.: High dispersed aerosols, in: Topics in Current Aerosol Research, edited by: Hidy, G. M., and Brock, J. R., Pergamon, New York, 1-59, 1971.

Heald, C. L., Jacob, D. J., Park, R. J., Russell, L. M., Huebert, B. J., Seinfeld, J. H., Liao, H., and Weber, R. J.: A large organic aerosol source in the free troposphere missing from current models, Geophys. Res. Lett., 32, L18809, doi:10.1029/2005GL0238312005.

Huffman, J. A., Ziemann, P. J., Jayne, J. T., Worsnop, D. R., and Jimenez, J. L.: Development and characterization of a fast stepping/scanning thermodenuder for chemically-resolved aerosol volatility measurements, Aerosol Sci. Technol., 42, 395-407, 2008.

Huffman, J. A., Docherty, K. S., Aiken, A. C., Cubison, M. J., Ulbrich, I. M., DeCarlo, P. F., D., S., Jayne, J. T., Worsnop, D. R., Ziemann, P. J., and Jimenez, J. L.: Chemically-resolved aerosol volatility measurements from two megacity field studies, Atmos. Chem. Phys. Discuss, in press, 2009.

Jayne, J. T., Leard, D. C., Zhang, X. F., Davidovits, P., Smith, K. A., Kolb, C. E., and Worsnop, D. R.: Development of an aerosol mass spectrometer for size and composition analysis of submicron particles, Aerosol Sci. Technol., 33, 49-70, 2000.

Jimenez, J. L., Jayne, J. T., Shi, Q., Kolb, C. E., Worsnop, D. R., Yourshaw, I., Seinfeld, J. H., Flagan, R. C., Zhang, X. F., Smith, K. A., Morris, J. W., and Davidovits, P.: Ambient aerosol sampling using the Aerodyne Aerosol Mass Spectrometer, J. Geophys. Res.-Atmos., 108, 8425, doi:10.1029/2001jd001213, 2003.

Joback, K. G. and Reid, R. C.: Estimation of pure-component properties from group-contributions, Chem. Eng. Commun., 57, 233243, 1987.

Johnson, D., Utembe, S. R., Jenkin, M. E., Derwent, R. G., Hayman, G. D., Alfarra, M. R., Coe, H., and McFiggans, G.: Simulating regional scale secondary organic aerosol formation during the TORCH 2003 campaign in the southern UK, Atmos. Chem. Phys., 6, 403-418, 2006, http://www.atmos-chem-phys.net/6/403/2006/.

Jonsson, A. M., Hallquist, M., and Saathoff, H.: Volatility of secondary organic aerosols from the ozone initiated oxidation of alpha-pinene and limonene, J. Aerosol Sci., 38, 843-852, doi:10.1016/j.jaerosci.2007.06.008, 2007.

Lim, Y. B. and Ziemann, P. J.: Products and mechanism of secondary organic aerosol formation from reactions of $n$-alkanes with $\mathrm{OH}$ radicals in the presence of NOx, Environ. Sci. Technol., 39, 9229-9236, doi:10.1021/Es051447g, 2005.

Morad, N. A., Kamal, A. A. M., Panau, F., and Yew, T. W.: Liquid 
specific heat capacity estimation for fatty acids, triacylglycerols, and vegetable oils based on their fatty acid composition, J. Am. Oil Chem. Soc., 77, 1001-1005, 2000.

Pankow, J. F.: An absorption-model of gas-particle partitioning of organic-compounds in the atmosphere, Atmos. Environ., 28, 185-188, 1994a.

Pankow, J. F.: An absorption-model of the gas aerosol partitioning involved in the formation of secondary organic aerosol, Atmos. Environ., 28, 189-193, 1994b.

Paulsen, D., Weingartner, E., Alfarra, M. R., and Baltensperger, U.: Volatility measurements of photochemically and nebulizergenerated organic aerosol particles, J. Aerosol Sci., 37, 10251051, doi:10.1016/i.jaerosci.2005.08.004, 2006.

Rader, D. J., McMurry, P. H., and Smith, S.: Evaporation rates of monodisperse organic aerosols in the 0.02-mu-m-diameter to 0.2-mu-m-diameter range, Aerosol Sci. Technol., 6, 247-260, 1987.

Reid, R. C., Prausnitz, J. M., and Poling, B. E.: Properties of gases and liquids, McGraw-Hill, New York, 741 pp., 1987.

Robinson, A. L., Donahue, N. M., Shrivastava, M. K., Weitkamp, E. A., Sage, A. M., Grieshop, A. P., Lane, T. E., Pierce, J. R., and Pandis, S. N.: Rethinking organic aerosols: Semivolatile emissions and photochemical aging, Science, 315, 1259-1262, doi:10.1126/science.1133061, 2007.

Seinfeld, J. H. and Pandis, S. J.: Atmosperic Chemistry and Physics, 1st Ed., John Wiley and Sons, Inc., New York, 1326 pp., 1998.

Stanier, C. O., Pathak, R. K., and Pandis, S. N.: Measurements of the volatility of aerosols from alpha-pinene ozonolysis, Environ. Sci. Technol., 41, 2756-2763, doi:10.1021/Es0519280, 2007.

Stanier, C. O., Donahue, N., and Pandis, S. N.: Parameterization of secondary organic aerosol mass fractions from smog chamber data, Atmos. Environ., 42, 2276-2299, 10.1016/j.atmosenv.2007.12.042, 2008.

Tao, Y. and McMurry, P. H.: Vapor-pressures and surface freeenergies of C14-C18 monocarboxylic acids and C5-dicarboxylic and C6-dicarboxylic acids, Environ. Sci. Technol., 23, 1519$1523,1989$.

Taylor, W. D., Allston, T. D., Moscato, M. J., Fazekas, G. B., Kozlowski, R., and Takacs, G. A.: Atmospheric photo-dissociation lifetimes for nitromethane, methyl nitrite, and methyl nitrate, Int. J. Chem. Kinetics, 12, 231-240, 1980.
Tobias, H. J. and Ziemann, P. J.: Compound identification in organic aerosols using temperature-programmed thermal desorption particle beam mass spectrometry, Anal. Chem., 71, 34283435, 1999.

Tobias, H. J., Kooiman, P. M., Docherty, K. S., and Ziemann, P. J.: Real-time chemical analysis of organic aerosols using a thermal desorption particle beam mass spectrometer, Aerosol Sci. Technol., 33, 170-190, 2000.

Ulbrich, I. M., Canagaratna, M. R., Zhang, Q., Worsnop, D. R., and Jimenez, J. L.: Interpretation of organic components from positive matrix factorization of aerosol mass spectrometric data, Atmos. Chem. Phys. Discuss., 8, 6729-6791, 2008, http://www.atmos-chem-phys-discuss.net/8/6729/2008/.

Volkamer, R., Jimenez, J. L., San Martini, F., Dzepina, K., Zhang, Q., Salcedo, D., Molina, L. T., Worsnop, D. R., and Molina, M. J.: Secondary organic aerosol formation from anthropogenic air pollution: Rapid and higher than expected, Geophys. Res. Lett., 33, L17811, doi:10.1029/2006g1026899, 2006.

Wang, S. C. and Flagan, R. C.: Scanning electrical mobility spectrometer, Aerosol Sci. Technol., 13, 230-240, 1990.

Wehner, B., Philippin, S., and Wiedensohler, A.: Design and calibration of a thermodenuder with an improved heating unit to measure the size-dependent volatile fraction of aerosol particles, J. Aerosol Sci., 33, 1087-1093, Pii S0021-8502(02)00056-3, 2002.

York, D., Evensen, N. M., Martinez, M. L., and Delgado, J. D.: Unified equations for the slope, intercept, and standard errors of the best straight line, Am. J. Phys., 72, 367-375, doi:10.1119/1.1632486, 2004.

Zhang, Q., Alfarra, M. R., Worsnop, D. R., Allan, J. D., Coe, H., Canagaratna, M. R., and Jimenez, J. L.: Deconvolution and quantification of hydrocarbon-like and oxygenated organic aerosols based on aerosol mass spectrometry, Environ. Sci. Technol., 39, 4938-4952, doi:10.1021/Es048568i, 2005. 